\title{
Functional studies of the coronavirus nonstructural proteins
}

\author{
Yanglin QIU and Kai XU* \\ Jiangsu Key Laboratory for Microbes and Functional Genomics, College of Life Sciences, Nanjing Normal University, Nanjing 210023, P. R. China. \\ *Correspondence: xukai@njnu.edu.cn \\ https://doi.org/10.37175/stemedicine.v1i2.39
}

\begin{abstract}
Coronaviruses, including SARS-CoV, SARS-CoV-2, and MERS-CoV, have caused contagious and fatal respiratory diseases in humans worldwide. Notably, the coronavirus disease 19 (COVID-19) caused by SARS-CoV-2 spread rapidly in early 2020 and became a global pandemic. The nonstructural proteins of coronaviruses are critical components of the viral replication machinery. They function in viral RNA transcription and replication, as well as counteracting the host innate immunity. Studies of these proteins not only revealed their essential role during viral infection but also help the design of novel drugs targeting the viral replication and immune evasion machinery. In this review, we summarize the functional studies of each nonstructural proteins and compare the similarities and differences between nonstructural proteins from different coronaviruses.
\end{abstract}

Keywords: Coronavirus $\cdot$ SARS-CoV-2 $\cdot$ COVID-19 $\cdot$ Nonstructural proteins $\cdot$ Drug discovery

\section{Introduction}

The coronavirus (CoV) outbreaks among human populations have caused three major epidemics worldwide, since the beginning of the $21^{\text {st }}$ century. These are the epidemics of the severe acute respiratory syndrome (SARS) in 2003 (1, 2), the Middle East respiratory syndrome (MERS) in $2012(3,4)$, and the coronavirus disease 19 (COVID-19) in 2020 (5-9).

Coronaviruses belong to the family Coronaviridae in the order Nidovirales (10). The Coronaviridae family has four genera, Alphacoronavirus, Betacoronavirus, Gammacoronavirus, and Deltacoronavirus. Currently, seven coronaviruses are known to infect humans. These include two alphacoronaviruses, human coronavirus 229E (HCoV-229E) (11) and HCoV-NL63 (12), as well as five betacoronaviruses, HCoV-OC43 (13), HCoV-HKU1 (14), SARS-CoV (15), MERS-CoV (4), and the novel coronavirus that causes COVID-19 (2019-nCoV) $(5,7,9)$. The 2019-nCoV was later renamed to SARS-CoV-2 by the International Committee on Taxonomy of Viruses (16), due to high sequence homology and same receptor requirements shared with SARS-CoV (9).

The genome of coronaviruses is a nonsegmented, positive-sense, single-strand RNA of about 28 - $32 \mathrm{nt}$ in length (17), which encodes for six major open reading frames (ORFs) and a various number of accessory

Received: Mar 13, 2020; Accepted: Mar 21, 2020

(c) The Author(s). 2019 This is an Open Access article distributed under the terms of the Creative Commons License (http://creativecommons.org/licenses/by/4.0/) which permits unrestricted use, distribution, and reproduction in any medium or format, provided the original work is properly cited. genes (18). The first two major ORFs (ORF1a, ORF1ab) are the replicase genes, and the other four encode viral structural proteins that comprise the essential protein components of the coronavirus virions, including the spike surface glycoprotein (S), envelope protein (E), matrix protein $(\mathrm{M})$, and nucleocapsid protein $(\mathrm{N})(14,19,20)$.

In the case of betacoronavirus, ORF1a translates into a polyprotein. It is subsequently cleaved into 11 nonstructural proteins (nsp1-11) by itself or by nsp3 and nsp5, which contains the papain-like (21) and Chymotrypsin-like protease activities (22), respectively. ORF $1 \mathrm{ab}$ is a polyprotein produced by translational readthrough of -1 ribosomal frameshift, which occurred at the coding region of nsp11. As a result, ORF $1 \mathrm{ab}$ polyprotein carries the nsp1-10 at its N-terminus and five more nonstructural proteins (nsp12-16) on the C-terminus. These nonstructural proteins synergistically form the cytoplasmic membranous organelle-like viral replication/ transcription complexes (TRCs) (23). Besides the essential roles in viral RNA replication and transcription (18, 24-33), nonstructural proteins also determine the viral pathogenesis $(18,29,34)$ as well as counteracting the cellular immune responses $(21,34-41)$. The coronavirus TRCs are among the most complex viral replication compartments (VRCs) known for positivestrand RNA viruses $(23,42,43)$.

Besides its complex nature, structures of most of the nonstructural proteins have been determined (26, 44-58). These structures not only provide the functional insights of nonstructural proteins but also help the design of novel drugs targeting the viral replication and immune evasion machinery $(47,59-62)$. These studies facilitate our 
understanding of how viruses establish their infection and provide the foundations for the development of efficient antiviral strategies. Here we summarize current knowledge on each nonstructural proteins of coronaviruses.

\section{Nsp1: the immune repressor}

Nsp1 is the very 5' proximal nonstructural protein of $\beta$-CoVs. It is released by PLpro at conserved proteolytic sites from polyprotein encoded by ORF1ab (63-65) (Reviewed in Table 1). Due to the severe outbreak of SARS in 2003, SARS-CoV nsp1 is among the most extensively studied. SARS-CoV nsp 1 is $20-\mathrm{kDa}$ in size and distributed in the cytoplasm when transiently expressed in 293 cells (66). It was first observed that SARS-CoV nsp1 transient expression strongly inhibited IFN- $\beta$ mRNA accumulation during Sendai virus infection, and promoted degradation of overexpressed exogenous mRNA and host endogenous mRNA, leading to an overall decrease in protein synthesis (66). Similar results were then obtained from studies on other $\beta$-CoVs including mouse hepatitis virus (MHV), bat coronavirus strains (Rm1, 133, and HKU9-1), and on a $\beta-\mathrm{CoV}$ human coronavirus 229E (HCoV-229E) $(67,68)$. These findings suggest that host translation arresting is a common feature during coronavirus infections.

The nsp1-mediated translation inhibition can be reproduced in the cell-free translation system (69). SARS-CoV nsp1 was demonstrated to bind and inactivate the $40 \mathrm{~S}$ ribosomal subunits, resulting in translational inhibition. Meanwhile, the nsp1 protein, in its $40 \mathrm{~S}$ ribosomal subunit binding form, could recruit a cellular endonuclease to mediate mRNA cleavage in the 5' untranslated region (5'-UTR) (70). Subsequently, 5'-truncated host mRNAs were degraded by host 5 ' - 3' exonuclease Xrn1 (71). Interestingly, protein translation under the control of internal ribosome entry site (IRES) from hepatitis $\mathrm{C}$ or cricket paralysis viruses, but not encephalomyocarditis virus, could escape from the SARSCoV nsp1-mediated RNA cleavage, possibly due to different requirement for translational initiation factors in forming $48 \mathrm{~S}$ initiation complex with the 40S subunit (69).

A SARS-CoV nsp1 mutant with two positively charged amino acid substitutions (R124A/K125A) loses the target mRNA/viral RNA binding and mRNA cleavage function but remains the ability to inhibit translation (72). MERSCoV nsp 1 contains the same RK motif. Nevertheless, this RK motif is not involved in binding to mRNAs but is required for the RNA cleavage. Instead, the R13 on the first alpha-helix of MERS-CoV nsp1 that is missing from SARS-CoV nsp1 is essential for mRNA binding (73).

Another SARS-CoV nsp1 mutant K164A/H165A was unable to bind to the $40 \mathrm{~S}$ subunit and lost the ability to interfere with host gene expression (69). When the same mutations (K164A/ H165A) were introduced to SARS$\mathrm{CoV}$ infectious clone, the recovered virus was replicationincompetent and unable to suppress innate immune responses or degrade host mRNA (66). A similar study was performed with MHV. MHV-nsp1- $\Delta 99$, which lacked 99 nucleotides in the nsp 1 coding region essential for host translation arresting, could not reproduce well in wild-type mice (67). Moreover, the MHV-nsp1- $\Delta 99$ mutant restored its replication to the wt virus level when infecting mice defected in the type I interferons (IFN-I) recognition, highlighting the role of nsp1 in counteracting the IFN-I (72). Notably, the SARS-CoV-2 nsp1 shares a high protein sequence identity of $84.44 \%$ with SARS-CoV nsp 1 , including R124/K125 for mRNA binding (red-colored) and cleavage (asterisked, Figure 1), K164/H165 for translation shutoff (green colored, Figure 1), suggesting a likely same role of SARS-CoV-2 nsp1 in counteracting host immune responses.

SARS-CoV genomic RNA and subgenomic RNAs are somehow resistant to the nsp1 induced RNA cleavage (70). The resistant element was mapped to the 5'-end leader sequence of SARS-CoV RNAs, which contains two important nucleotides AU at the very 5' terminal, followed by AUUA. Coincidently, the SARS-CoV-2 genome also starts with the same two nucleotides AU, followed by UAAA. Whether SARS-CoV-2 avoids nsp1 mediated RNA cleavage by the same RNA coding remains to be answered.

\section{Nsp2: fine-tuner of replication}

Nsp2 is the most variable nonstructural protein among

Table 1 Proteolysis sites of the ORF1a/ORF1ab polyproteins. The polyproteins were cleaved by the nsp3 papain-like protease and the nsp5 3C-like protease, resulting in the release of sixteen nonstructural proteins. The position of the scissors represents the cleavage site.

\begin{tabular}{|c|c|c|c|c|c|}
\hline & & a & 20 & $k$ & 89 \\
\hline & nsp1 & nsp2 & nsp3 & nsp4 & nsp5 \\
\hline SARS-CoV-2 & $\cdots$ ELNGG & AYTR $\cdots$ TLKGG & APTK $\cdots$ ALKGG & 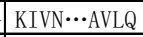 & SGFR $\cdots$ VTFE \\
\hline \begin{tabular}{|l|} 
SARS-CoV \\
\end{tabular} & $\cdots$ ELNGG & AVTR $\cdots$ RLKGG & APIK $\cdots$ SLKGG & KIVS $\cdots$ AVLQ & SGFR $\cdots$ VTFQ \\
\hline \begin{tabular}{|l|} 
MERS-CoV \\
\end{tabular} & $\cdots$ KLIGG & DVTP $\cdots$ RLKGG & APVK $\cdots$ KIVGG & APTW $\cdots$ GVLQ & SGLV $\cdots$ VVMQ \\
\hline
\end{tabular}

\begin{tabular}{|c|c|c|c|c|c|c|c|c|c|c|c|c|}
\hline & nsp5 & nsp6 & nsp7 & nsp8 & nsp9 & nsp10 & nsp11 & nsp12 & nsp13 & nsp14 & nsp15 & nsp16 \\
\hline SARS-CoV-2 & SGFR $\cdots$ VTFQ & SAVK $\cdots$ ATVQ & SKMS $\cdots$ ATLQ & AIAS $\cdots$ VKLQ & NNEL $\cdots$ VRLQ & AGNA $\cdots$ PMLQ & SADA $\cdots$ & -.TVLQ & AVGA $\cdots$ ATLQ & AENV $\cdots$ TRLQ & SLEN $\cdots$ PKLQ & SSQA $\cdots$ \\
\hline SARS-CoV & SGFR $\cdots$ VTFQ & GKFK $\cdots$ ATVQ & SKMS $\cdots$ ATLQ & AIAS $\cdots$ VKLQ & NNEL $\cdots$ VRLQ & AGNA $\cdots$ PLMQ & SADA $\cdots$ & $\cdots$ TVLQ & AVGA $\cdots$ ATLQ & AENV $\cdots$ TRLQ & SLEN $\cdots$ PKLQ & $\operatorname{ASQA} \cdots$ \\
\hline MERS-CoV & SGLV $\cdots V V V Q$ & SGVR $\cdots$ AAMQ & SKLT $\cdots$ SVLQ & ATLS $\cdots$ VKLQ & NNEI $\cdots$ VRLQ & AGSN $\cdots$ AALP & QSKD $\cdots$ & \begin{tabular}{|c|} 
TVLQ \\
\end{tabular} & AVGS $\cdots$ YKLQ & SQIV $\cdots$ TKVQ & GLEN $\cdots$ PRLQ & $\operatorname{ASAD} \cdots$ \\
\hline
\end{tabular}



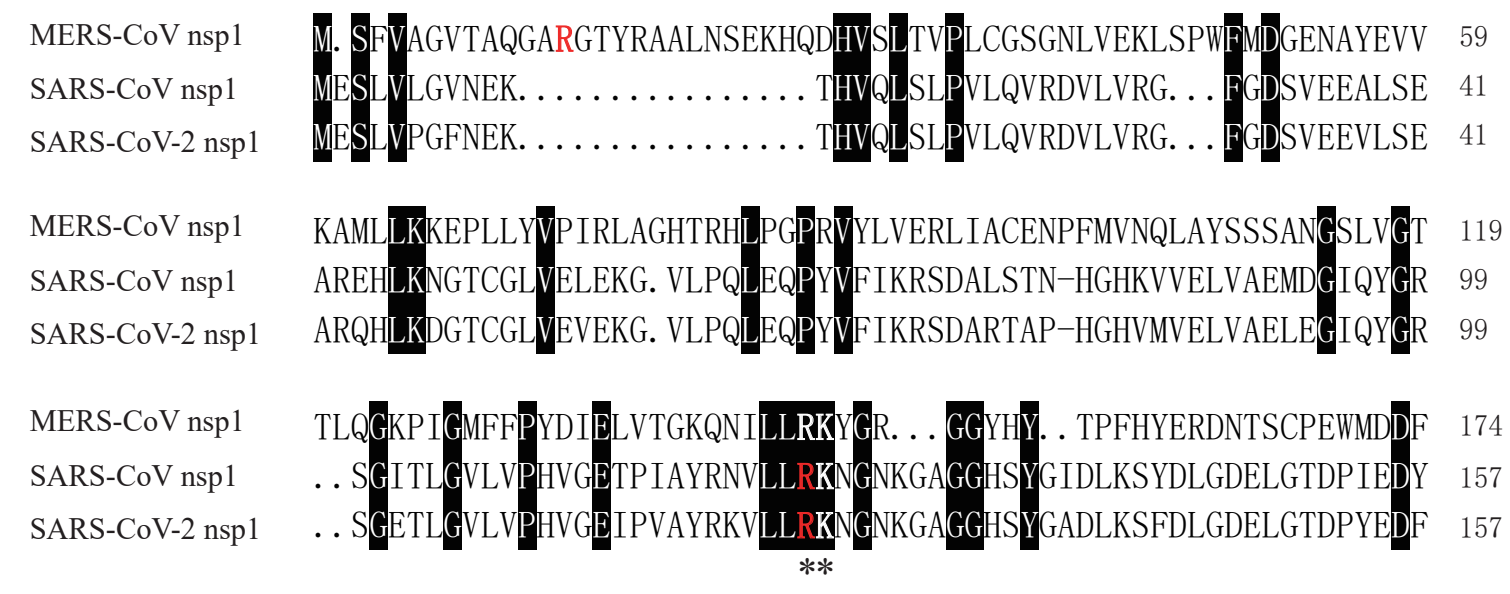

$\begin{array}{lll}\text { MERS-CoV nsp1 } & \text { EADPKGKYAQN. . . . LLKKLIGG } & 193 \\ \text { SARS-CoV nsp1 } & \text { EQNWNTKHGSGALRELTRELNGG } & 180 \\ \text { SARS-CoV-2 nsp1 } & \text { QENWNTKHSSGVTRELMRELNGG } & 180\end{array}$

Figure 1. Alignment of nsp1 protein sequences of MERS-CoV, SARS-CoV, and SARS-CoV-2. The sequences of nsp1 from MERSCoV (accession no. JX869059), SARS-CoV (accession no. AY278741), and SARS-CoV-2 (accession no. NC_045512) were aligned, and identical amino acids are highlighted. Amino acids essential for mRNA binding are colored in red, while those responsible for host translation shutoff are colored in green. Asterisked are the sites important for RNA cleavage.

SARS CoV-related viruses (74). A comparative analysis of the protein sequences of SARS-CoV-2 with SARSCoV showed 61 amino acid substitutions in nsp2 between these two viruses (20). Due to the sequence variability of nsp2 among coronaviruses, it was speculated that nsp2 protein coevolved with the hosts to acquire host-specific functions, and modulating infection (75). A study utilizing nsp2-deleted MHV or SARS-CoV recombinant clones showed that nsp2 is required for optimal viral replication (30). When the nsp2 was deleted from the viruses, the viral titer, and viral RNA synthesis rate moderately reduced compared to the wild type virus. Nsp2 is shown to localize to the viral TRCs (43). However, MHV mutant with nsp2 deletion did not affect the morphology and subcellular localization of the TRCs (30). Importantly, Nsp2 expressed from other genomic loci still could not rescue the replication deficiency, pointing out that the function of nsp2 in viral growth depends on its correct genomic loci between nsp1 and nsp3 (76). Nsp2 was known to from nsp2-nsp3 proteolytic intermediate (30). Nsp2 may regulate protease cleavage in the form of nsp2-nsp3, thus fine-tuning the viral replication.

\section{Nsp3: the scaffold protein and protease}

Nsp3 is the largest among all the nonstructural proteins of $\beta$-CoV. It is cleaved off from ORF1a/ORF1ab by the papain-like protease domain or PL $2^{\text {pro }}$ domain that is within nsp3 itself. The function of nsp3 is to mediate the genome replication/transcription (77-80) and pathogenesis (81). Due to its large size and complex domain organization, nsp3 interacts with other nonstructural proteins $(77,78)$, structural proteins $(79,80)$, and host proteins (62) as a scaffold during viral infection (33). The SARS-CoV or SARS-CoV-2 nsp3 contains 16 domains (Figure 2), namely Ubiquitin-like domain 1
(Ubl1), Hypervariable region (HVR) or acidic domain, Macrodomain I/II/III (MacI/II/III), Domain Preceding Ubl2 and PL2 ${ }^{\text {pro }}$ (DPUP), Ubiquitin-like domain 2 (Ubl2), Papain-like protease two domain (PL2 ${ }^{\text {pro }}$ ), Nucleic acidbinding domain (NAB), betacoronavirus-specific marker domain ( $\beta S M)$, Transmembrane domain 1 (TM1), Nsp3 ectodomain (3Ecto), Transmembrane domain 2 (TM2), Amphipathic helix region (AH1), domains specific to Nidovirales and Coronaviridae (Y1 \& CoV-Y) (82). These domains function synergistically to regulate viral infection.

Ubl1 is the first domain that locates on the N-terminus of $\beta-\mathrm{CoV}$ nsp3. The Nuclear magnetic resonance (NMR) structure of Ubll showed that the Ubll domain is structurally similar to ubiquitin-like proteins, albeit two additional helices $\left(3_{10}\right.$ helix and $\alpha$ helix) make the core structural more oval other than globular, comparing to human Ubiquitin or ISG15 $(58,82)$. Ubiquitination and ISGylation are associated with host regulation of innate antiviral responses (83-86), but the role of mimicry of ubiquitin by ubl1 (as well as ubl2) is currently unknown. It is reasonable to speculate that the ubiquitin-like domains of nsp 3 could bridge the protease function of nsp3 to ubiquitination machinery in the cell and interfere with host antiviral immunity.

Ubl1 domain of nsp3 was shown to predominantly bind to single-stranded trinucleotide RNA sequence AUA, as mass-spectrometry analysis of the purified recombinant SARS-CoV Ubl1 from E. Coli. revealed co-purified unique RNA fragments (58). It is noted that both SARS$\mathrm{CoV}$ and SARS-CoV-2 have AU-rich 5'-UTR or even 5' terminus in their genomic or subgenomic RNAs $(20,70)$. Whether this coincidence has a functional role remains to be tested. In addition to the studies on SARS-CoV, the Ubl1 domain of MHV nsp3 was found to bind to the viral. 
$\mathrm{N}$ protein (80). This interaction is essential for $\mathrm{N}$ proteinmediated enhancement of viral infectivity (79).

The HVR domain locates at the C-terminus of the Ubll domain. HVR, also known as acidic domain, is rich in negatively charged amino acids aspartic acid (Asp/D) and glutamic acid $(\mathrm{Glu} / \mathrm{E})$. As its name indicates, it is the most variable region found in nsp3. Amino acids sequence identity between SARS-CoV HVR and SARS-CoV-2 HVR is $47.14 \%$, much lower than the $76.6 \%$ overall nsp3 amino acid sequence identity. The HVR region is

Ubl1

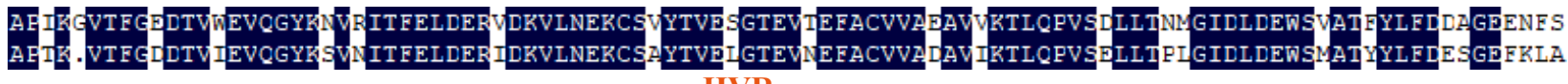
HVR

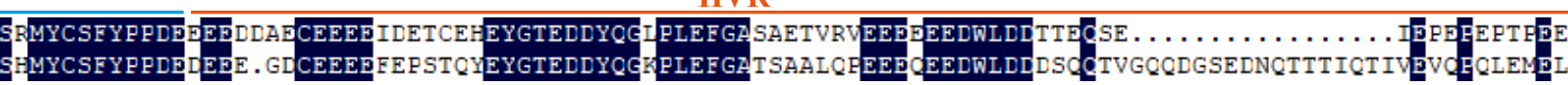

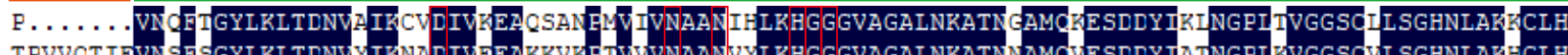

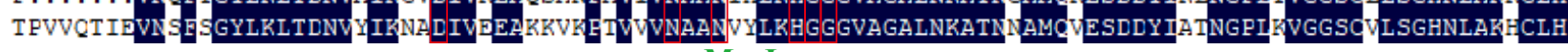
MacI

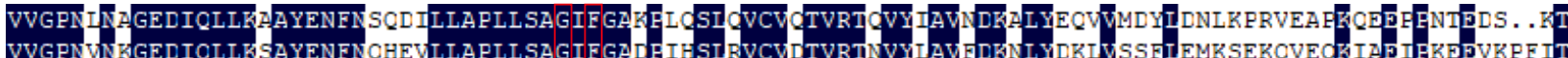
MacII

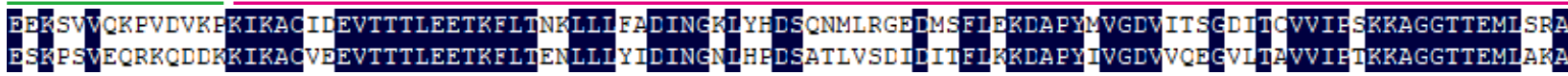

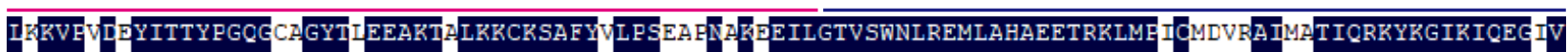
IRKVHIDNYITTYPGQGLNGYTVEEAKTVLKKCKSAFYILPSIISNEKCEIL GTVSWNLREMLAHAEETRKLMEVGVETKAIVSTIQRKYKG IKIQEGVV MacIII

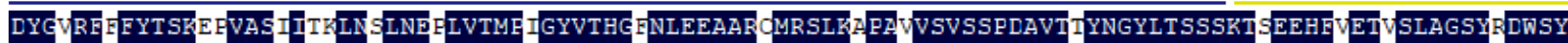
DYGARAYFYTSKT TVASI INILNDLNGTLVTMEI GYVTHGLNLEEAARYMRSLKVEA TVSVSSPDAVTZYNGYLTSSSKTEEEHEIETISLAGSYKDWSY

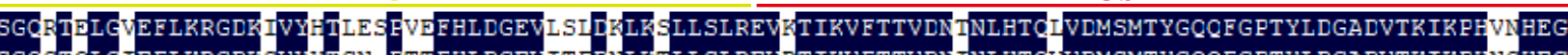

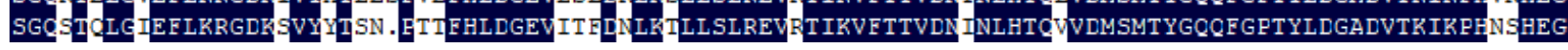

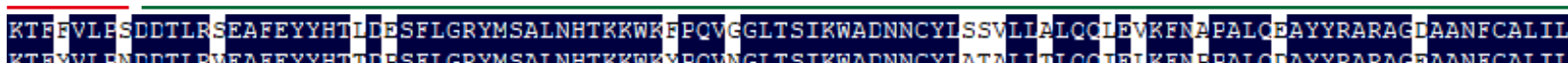

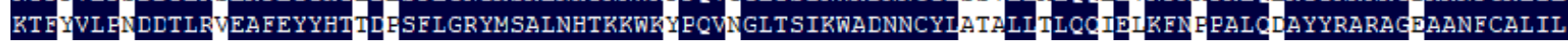
PL2 ${ }^{\text {pro }}$

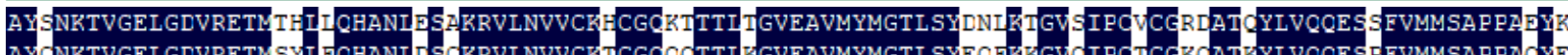

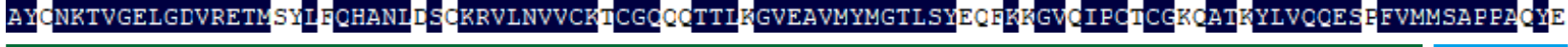

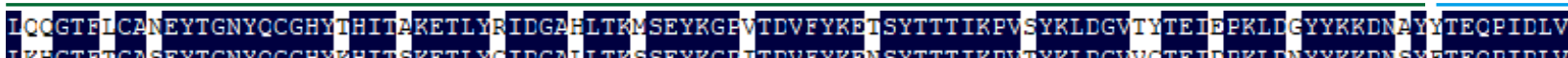

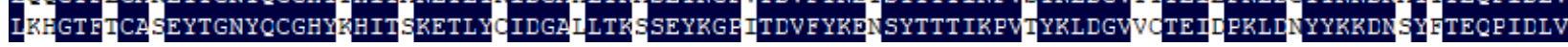
NAB

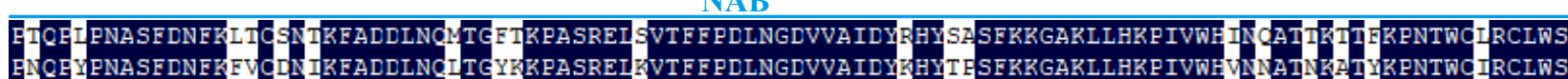

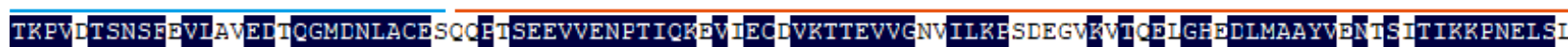

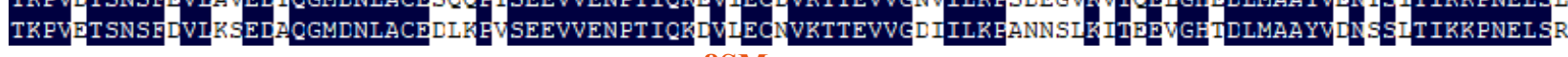
BSM

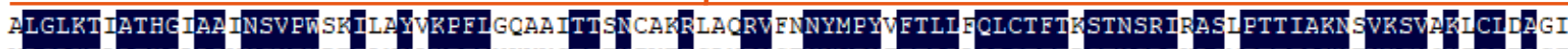

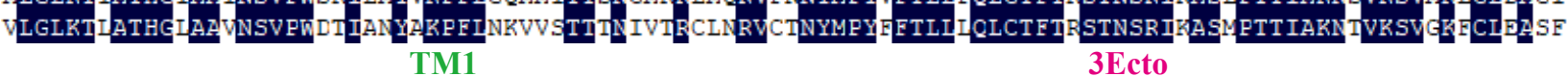

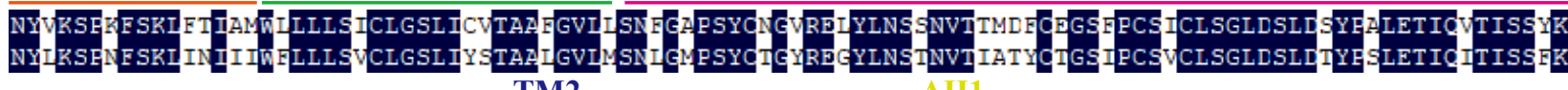
TM2

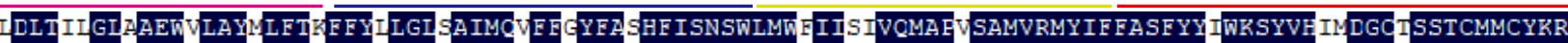

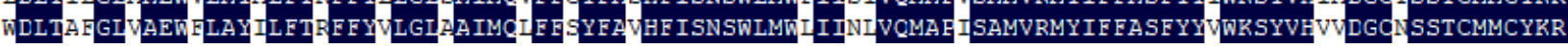
NRATRVECTT IVNGMKRSFYVYANG $R$ GFCKTHNWNGINCDTFGTGSTF ISDEVARDLSLQFKRPINPTDQSSYIVDSVZVKNGAIHLYF DKAGQKTYER NRATRVECTT IVNGVRRSFYVYANGGKGFCKLHNWNOVNCDTFCZGSTF ISDEVARDLSLQFKRP INPTDQSSYIVDSVTVKNGS IHLYFDKAGQRTYER $\mathrm{Y} 1 \& \mathrm{CoV}-\mathrm{Y}$

FFLSHFVNLDNLRANNTKGSLPINVIVFDGKSKGDESA SKSASVYYSQLMCQPILLLDQALVSDVGDSTEVSVKMFDAYVITFSITFSVPMEKLFPIVAT HSLSHFVNLDLRANNTKGSLP INVIVF DGKSKCEESSAKSASVYYSQLMCQPILLLDQALVSDVGDSZEVZVKMFDAYVTFSST FNVPMEKLKTLVAT

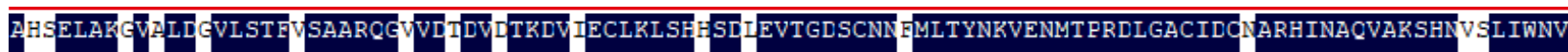

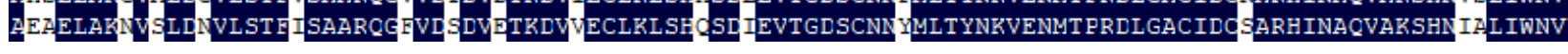


A.

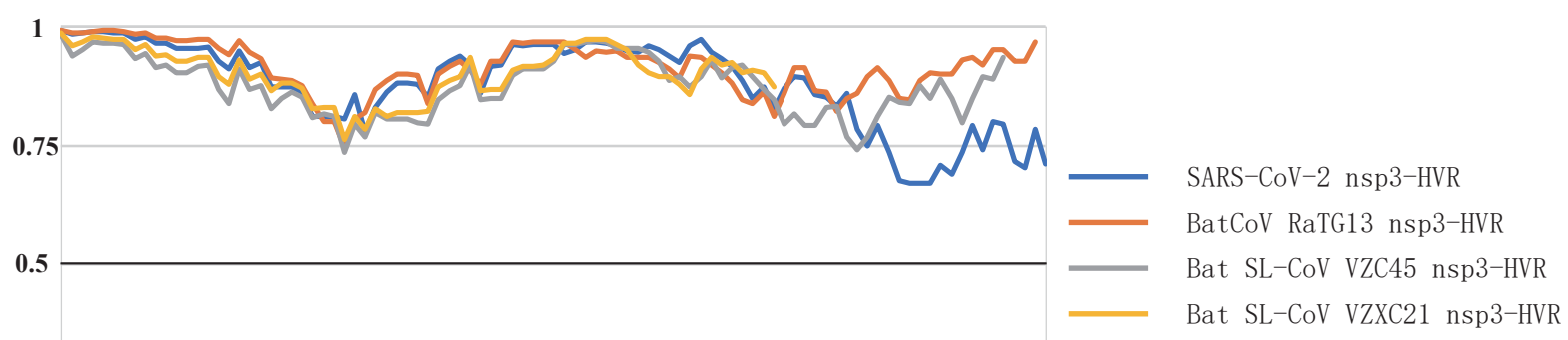

0.25

$\begin{array}{llllllllll}0 & 11 & 21 & 31 & 41 & 51 & 61 & 71 & 81 & 91\end{array}$

B.

SARS-CoV-2 nsp3-HVR
BatCoV RaTG13 nsp3-HVR
Bat SL-CoV VZC45 nsp3-HVR
Bat SL-CoV VZXC21 nsp3-HVR
SARS-CoV-2 nsp3-HVR
BatCoV RaTG13 nsp3-HVR
Bat SL-CoV VZC45 nsp3-HVR
Bat SL-CoV VZXC21 nsp3-HVR
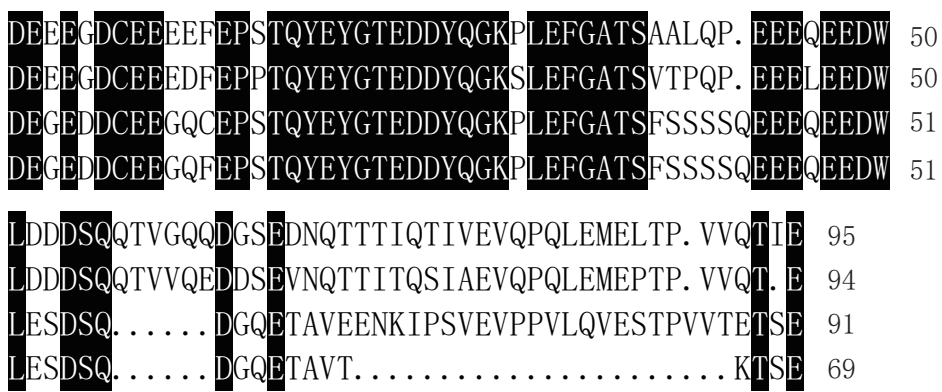

EDNQT
EVNQT
ETAVT

Figure 3. The HVR region of SARS-CoV-2 and its hypothetical ancestors is intrinsically disordered. A. The degree of disorder is shown graphically based on the analysis of IUPred2A (226). A score of more than 0.5 is considered disordered. B. The alignment of HVR region shows a high degree of negatively charged amino acid percentage in conserved amino acids.

intrinsically disordered in SARS-CoV (58) and MHV (57). The same feature is also observed in SARS-CoV-2 as well as in three highly similar bat coronavirus isolates BatCoV RaTG13 (accession no. MN996532) (9), Bat SLCoV VZC45 (accession no. MG772933), and Bat SLCoV VZXC21 (accession no. MG772934) (63) which show high nucleotide identity and protein identity to SARS-CoV-2 (Figure 3A). There are 45 consensus amino acids in the HVR among SARS-CoV-2 and these three bat viruses (Figure 3B), of which $48.9 \%$ are Asp/Glu. In the nonconsensus regions, the Asp/Glu percentage is $20 \%, 20.4 \%, 15.2 \%$, and $8.3 \%$ for SARS-CoV-2, BatCoV RaTG13, Bat SL-CoV VZC45, and Bat SL-CoV VZXC21, respectively, and is much lower than that of the consensus sequence. These differences of HVR Asp/Glu percentage between consensus and nonconsensus regions indicate a possible function of negatively charged amino acids in viral replication that was selected during viral evolution. But currently, the exact role of HVR in the viral life cycle is unknown, studies on MHV suggest HVR is dispensable for viral infection in vitro (79).

Following the HVR is the Macrodomain I (MacI, previously known as $\mathrm{X}$ domain). Macrodomains are evolutionarily conserved domains that are ubiquitously existing in prokaryotes and eukaryotes. Three decades ago, bioinformatic analyses identified that members in
Coronaviridae, Togaviridae, and Hepeviridae families encode this conserved domain of an unknown function, to which the name $X$ domain was given $(29,59,87-89)$. Protein crystallography studies on macrodomains of SARS-CoV (90,91), MERS-CoV (54), and other coronaviruses $(55,56,90)$ showed a three-layered alpha/beta/alpha core fold similar to the C-terminal nonhistone region of MacroH2A, a variant of human histone H2A (92). Macrodomains of SARS-CoV and some other coronaviruses contain in vitro ADP-ribose1 "-phosphate phosphatase (ADRP) activity $(90,91)$, demono-ADP-ribosylation (deMARylation) activity (36), and de-poly-ADP-ribosylation (dePARylation) activity (93). Studies by using a series of mutations on SARS-CoV and MHV showed that ADRP, deMARylation, and dePARylation activities of MacI are essential to viral virulence in vivo by suppressing the innate immune responses $(36,81,91)$. These sites are conserved between SARS-CoV and SARS-CoV-2 (29) (Figure 2, boxed in red).

The SARS-CoV MacII+MacIII+DPUP forms a previously recognized SARS-unique domain (SUD), although more reports on betacoronavirus genome sequences suggest that this domain is not unique to SARS$\mathrm{CoV}$ (94). MacII is the second marcodomain locating at the C-terminal side of MacI, and is dispensable for SARS$\mathrm{CoV}$ replicon replication, while the third macrodomain 
(MacIII) is required for SARS-CoV replication (32). MacIII binds to the G-quadruplexes formed by the Quadruplex forming G-Rich Sequences (QGRS) located in the nsp2 and nsp12 coding region (95). The MacII-III region also preferentially binds to oligo $(\mathrm{G})$-strings, which are present in the 3'-UTR of human mRNAs encoding defense-related genes (96). These RNA binding features are possibly essential for viral replication. DPUP is the domain that follows the MacIII. SARS-CoV lacking this domain displays reduced viral RNA even though the virus is still viable (32). Although the DPUP of SARS-CoV and MHV resembles a frataxin-like structure (95), which may involve controlling cellular oxidative stress (97, 98), the exact role of DPUP in viral infection is currently unknown.

$\mathrm{Ub12}+\mathrm{PL} 2^{\text {pro }}$ locates immediately downstream of DPUP. $\mathrm{Ubl} 2+\mathrm{PL} 2^{\text {pro }}$ of SARS-CoV and MERS-CoV were shown to modulate host innate immune responses $(35,99)$, albeit such immune suppression activity was separately reported to be only restricted in PL2 ${ }^{\text {pro }}$ (41). Papainlike protease $2\left(\mathrm{PL}^{\mathrm{pro}}\right)$ is the protease domain within nsp3, which recognizes conserved motifs (Table 1) in the conjunction part of nsp1/nsp2, nsp2/nsp3, and nsp3/ nsp4. In SARS-CoV and SARS-CoV-2, these motifs share XLXGG $\downarrow$ pattern, in which $\downarrow$ is the cleavage site. MERS$\mathrm{CoV}$ contains the same pattern except for the cleavage site between nsp 3 and nsp4 is KIVGG $\downarrow$. These protease processing sites resemble the very $\mathrm{C}$-terminal ends of ubiquitin and ubiquitin-like protein ISG15 (53), which is RLRGG and can be removed by deubiquitinating enzymes and deISGylating enzymes. Interestingly, the PL2 $2^{\text {pro }}$ also possesses DUB and deISGylating activities besides its proteolytic activity $(21,41,100-102)$. Ubiquitination and ISGylation play a central role in immune responses against viruses $(85,86,103)$. Membrane-anchored SARSCoV PL2 ${ }^{\text {pro }}$ domain (PL2 ${ }^{\text {pro }}-\mathrm{TM}$ ) could physically interact with STING (stimulator of IFN genes) - TRAF3 (The tumor necrosis factor receptor-associated factor 3) -TBK1 (TANK-binding kinase 1) complex and deubiquitinate intracellular dsRNA sensor RIG-I, STING, TRAF3, TBK1, and the transcription factor interferon regulatory factor 3 (IRF3) which cascadingly activate the IFN- $\beta$ production pathway (104). SARS-CoV PL2 $2^{\text {pro }}$ also removes Lys63-linked ubiquitin chains of TRAF3 and TRAF6, leading to suppression of the TLR7 signaling pathway (105). Human coronavirus NL63 (HCoV-NL63) deubiquitinates and stabilizes the E3 ubiquitin ligase MDM2 to increase the degradation of tumor suppressor p53 (40). Besides its DUB and deISGylating activities, coronavirus papain-like protease also depends on its interaction with host proteins to counteract host antiviral responses (106).

The NAB domain, which only exists in betacoronaviruses (94), forms flexibly extended linkers between the PL2 ${ }^{\text {pro }}$ domain and the following domains of nsp3 (52). NAB domain could bind to RNA, especially repeats of GGGs (52), similar to the RNA recognition pattern of MacIII (95). Betacoronavirus-specific marker $(\beta \mathrm{SM})$ domain follows $\mathrm{NAB}$ within nsp3. SARS-CoV $\beta \mathrm{SM}$ is intrinsically disordered (82), and its role in the viral life cycle is currently unknown.

Downstream of $\beta \mathrm{SM}$ domain is the transmembrane region that contains two transmembrane domains (TM1/2) and one luminal loop domain (3Ecto) (94). Subcellular localization analysis of SARS-CoV nsp3 truncated mutants revealed that the TM1/2 and the luminal 3Ecto domain are essential for the recruitment of nsp4 to discrete ER loci (78). The luminal 3Ecto domain of nsp3, possibly forming a disulfide bond, was proposed to interact with the luminal domains of nsp4 to "zipper" the ER membrane and induce discrete membrane formation (78). This membrane modification was recognized as the first step in forming the ER-origin viral replication organelles (28). Nsp3-nsp4 interaction of MERS-CoV also leads to the zippering of ER membranes and subsequent formation of DoubleMembrane Vesicles (DVMs) (107).

$\mathrm{AH} 1+\mathrm{Y} 1 \& \mathrm{CoV}-\mathrm{Y}$ domain is the C-terminal portion of nsp3 that is facing towards the cytosol. AH1 encodes a predicted transmembrane domain that was shown to be a cytosolic region in SARS-CoV and MHV (42). Currently, the functions of these domains are less well understood as the N-terminal nsp3.

\section{Nsp4: the DVM builder}

Coronavirus nsp4 is an integral membrane protein with four transmembrane domains (42). In partnership with nsp3, it plays an essential role in the formation of the membranous structure of TRCs $(27,107,108)$. SARSCoV or MERS-CoV nsp4/nsp3 localized to the reticular ER membrane when expressed separately $(78,107)$. However, when nsp4 and nsp3 were coexpressed, the formation of distinct perinuclear loci representing stacked double ER membranes was observed (78, 107). Such membrane rearrangements represent the critical step in TRCs formation. The N-terminus nsp4, including the first transmembrane domain and the first luminal loop region between TM1 and TM2, is required for this membrane rearrangement (78). The C-terminal TM4 and cytosolic part of nsp4 are dispensable for either formation of SARS$\mathrm{CoV}$ induced aggregated ER loci (78), or efficient viral growth of MHV (27).

This first luminal region of SARS-CoV nsp4 could interact with the nsp3 luminal 3Ecto domain to bring two ER membranes in close proximity (109). This region was predicted to be glycosylated for various of coronaviruses (108). When glycosylated sites of this region were mutated in MVH, viral growth was reduced along with deficient DVM formation (108). Two-amino acid changes (H120N/ F121L) near the SARS-CoV nsp4 glycosylation site (N131) abolished the nsp4-nsp3 interaction and also led to reduced genome replication and viral production (109). Comparing with SARS-CoV, the emerging SARS-CoV-2 contains same sites including both nsp3-interacting H120/ F121 and the N131 glycosylation site (Figure 4).

\section{Nsp5: the main protease}

Coronavirus nsp5 encodes an enterovirus 3C-like protease $\left(3 \mathrm{CL}^{\mathrm{pro}}\right)$ conserved across the Nidovirales (19). 


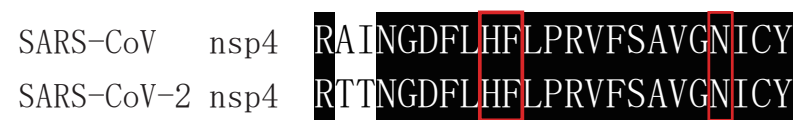

134

134

Figure 4. SARS-CoV-2 and SARS-CoV nsp4 share identical amino acids responsible for DVM formation.

It is a cysteine protease with a chymotrypsin-like fold and is often referred to as the main protease (Mpro). Similar to the PL2 $2^{\text {pro }}, 3 \mathrm{CL}^{\text {pro }}$ is essential to the nonstructural protein processing by cleavage at 11 sites downstream of the nsp4 coding region (Table 1). SARS-CoV nsp5 consists of an $\mathrm{N}$-terminal domain with proteolytic activity, as well as a C-terminal domain that contains five alpha-helices $(22,51$, $110,111)$. SARS-CoV $3 \mathrm{CL}^{\text {pro }}$ has at least three formats, an inactive monomer $(22,112)$, an active homodimer $(22$, $51,111,112)$, and a highly active homooctamer (110). Besides its proteolytic activity, porcine deltacoronavirus (PDCoV) nsp5 cleaves Signal transducer and activator of transcription 2 (STAT2) at two locations with glutamine (Q) residue at the $\mathrm{P} 1$ position, leading to the inhibition on the transcription of IFN-stimulated genes (39). Deltacoronavirus nsp5 also targets the NF- $\mathrm{BB}$ essential modulator (NEMO) for degradation and also suppresses type I IFN production $(37,38)$. Thus, coronavirus nsp5 assists viral infection by proteolytically releasing nsp416 , and suppresses innate immune responses by digesting essential enzymes in the immune signal transduction pathway.

\section{Nsp6: forming DVM and activating autophagy}

Coronavirus nsp6 is a transmembrane protein with six transmembrane domains (77). When expressed alone, it localized to ER and induced the generation of DFCP1 (Double FYVE domain-containing protein 1) positive early autophagosomes, or omegasomes. Such a structure can mature into autophagosomes that are capable of delivering LC3 for lysosomal degradation (113). Autophagy is not required for either coronavirus replication or antiviral responses in vitro. The knockout of ATG5 or ATG7, essential genes in the autophagy pathway, does not affect betacoronavirus MHV replication $(114,115)$. ATG5 silencing in Vero cells or treatment with wortmannin, the class 3 PI3K inhibitor, also does not affect replication of the Infectious bronchitis virus (IBV), a gammacoronavirus, (113). Although induction of autophagy is not required for coronavirus genome replication, the nsp6 plays a vital role in the viral life cycle. Coronavirus encodes three nonstructural proteins with transmembrane domains, nsp3, nsp4, and nsp6. While nsp3+nsp4 only produces aggregated zippered ER structures or maze-like body, nsp6 expression in addition to nsp3+nsp4 leads to the DMVs formation (77), resembling the authentic membranous structures of TRCs (77). Two HCoV-229E mutants, both contain single amino acid mutation on nsp6, confer antiviral drug K22 resistant, and result in partial recovery of drug-related DVMs loss. These mutations affected progeny infectivities, suggesting that nsp6 is critical for the viral life cycle (61). Although nsp6 expression induces autophagosomes-like DVMs, coronaviruses do not require autophagy for viral replication. Nsp6 or coronavirus likely recruits some host proteins shared with the autophagy pathway for viral DVMs production. However, such speculation needs further investigation.

\section{Nsp7+Nsp8: the RdRp cofactor}

Coronavirus nsp7 and nsp 8 are indispensable and essential for viral survival (116). The crystal structure of SARS-CoV nsp7 with nsp8 is a hollow cylinder-like supercomplex, formed by two asymmetric units. Each unit includes four nsp7 and four nsp8 (26). In the nsp7+nsp8 supercomplex, a channel structure is apparent (26). The channel is mainly formed by the bridging of the four long helices of N-terminus nsp8, of which the structure resembles the "shaft" of a "golf-club" (26). Mutations on the positive-charged amino acids on this "shaft" region significantly reduce dsRNA binding ability of the supercomplex, while the mutations of positive-charged amino acids on nsp7 near the channel structure do not (26). Unlike nsp12, nsp8 is a non-canonical RNA-dependent RNA polymerase (RdRp) that does not encode the conserved RdRp motif (117). SARS-CoV nsp8 could initiate short oligonucleotide $(<6 \mathrm{nt})$ synthesis at an internal template cytidine with a distance of at least two nucleotides from the 3 '-end (117). A later study misinterpreted this internal initiating primer synthesis ability from nsp8 as the de novo initiation (118). In this study, the authors also reported that nsp8 has primer extension activities (118). The association of nsp8 with nsp7 was shown to enhance thermal stability (117) and primer extension activity of nsp8 (118). Thus, SARSCoV nsp8, together with nsp7, provides RNA primer internally complementary to the viral genomic RNA for viral replication, which also requires the "main" RdRp nsp12 (119).

Nsp7+nsp8 complex of feline coronavirus (FCoV), an alphacoronavirus, is a $2: 1$ heterotrimer containing two conformational different nsp7 molecules and one nsp8 molecule. Two copies of heterotrimers could bind to each other through nsp8-nsp8 interaction and form a heterohexamer (120). This nsp7+nsp8 complex is also capable of synthesizing short oligonucleotides (120). Similar to FCoV, the alphacoronavirus HCoV-299E nsp710 polyprotein has this noncanonical RdRp activity as well (120).

However, due to the internal initiation nature of the nsp8 primase, the model including primer synthesis of nsp8 plus the primer-dependent RdRp activity of nsp12 still could not provide mechanism insights for the viral RNA 
synthesis of the 5'-end. On the other hand, a later study on the $n s p 7+n s p 8+n s p 12$ complex showed that this protein complex possesses both de novo initiation and primer extension RdRp activities. In this work, the nsp7+nsp8 complex indeed misses the de novo initiation activity, suggesting that this activity is mediated by nsp12 (119). Furthermore, the primase activity of nsp 8 was not observed (119). Recently a single particle cryo-electron microscopic structure of nsp12 with nsp 7 and nsp8 shows a heterodimer of $n s p 7+n s p 8$ as well as second $n s p 8$ subunit binding to the N-terminal region of nsp12 (44). This structure favors biochemically established de novo initiation activity of nsp7+nsp8+nsp12 complex (119), where nsp7+nsp8 does not mediate RNA primer synthesis or form the higher-order oligomer $(26,117)$.

In SARS-CoV infected Vero cells, nsp8 can be detected as two forms, a $22 \mathrm{kDa}$ full-length protein and a $\sim 15 \mathrm{kDa}$ version (65). The later was confirmed to be N-terminally truncated version (nsp8C) by western blotting analysis using an antibody only recognizing the C-terminal part (121). $\mathrm{Nsp} 7+\mathrm{nsp} 8 \mathrm{C}$ forms a structure that displays the ability to fuse into the nsp $7+$ nsp 8 hexadecamer and was proposed to help the virus switch the replication to genome assembly (121).

\section{Nsp9: the dimer forming RNA binding protein}

Nsp9 is a $\sim 12 \mathrm{kDa}$ proteolytic cleavage product of ppla that has the nucleic acid binding activity $(45,122)$. It preferentially binds to single-stranded RNA (45, 122, 123). Biotin pull-down assay showed that IBV nsp9 preferentially interacts with the 3'-UTR region of the positive-strand viral RNA $(124,125)$. Nsp9 can interact with itself as well as the non-canonical RdRp nsp8 (124127). Like most of the coronavirus nonstructural proteins, it locates in the viral TRCs $(65,128)$.

The crystal structure of the nsp 9 monomer revealed a cone-shaped N-terminal $\beta$-barrel composed of seven $\beta$-strands and a $\mathrm{C}$-terminal $\alpha$-helix that is conserved among alpha-, beta, and gamma-CoVs $(45,122,123$, 129, 130). However, its dimerization varies among different coronaviruses. SARS-CoV, IBV, and porcine delta coronavirus (PDCoV) nsp9 were reported to form the "parallel helix-dimer" structure that stabilized by the hydrophobic interactions between two C-terminal $\alpha$-helices. PDCoV nsp9 dimer is slightly different in that it also requires the $\mathrm{N}$-terminal extended finger motif to stabilize the dimer structure. Besides, SARS-CoV nsp9 can form the "sheet-dimer" structure formed by interactions between $\beta$-strand five from both subunits (45). HCoV-229E nsp9 forms an "anti-parallel helix dimer" that requires interaction between two $\alpha$-helices in the opposite direction with disulfide-bond from two nsp9 subunits (123). The porcine epidemic diarrhea virus (PEDV) nsp9 forms two possible dimer structure resembles the "parallel helix-dimer" and "sheet-dimer" stabilized by a disulfidelinkage (129).

Albeit various of dimerization structures, the dimer formation could enhance the nucleic acid binding and viral replication $(123,129-131)$. Mutations of the proteinprotein interaction motif GXXXG on the C-terminal $\alpha$-helix of SARS-CoV nsp9 disrupted dimer formation, and significantly decreased RNA binding of nsp9. The corresponding mutations in the SARS-CoV genome were either lethal to the viral growth or reverted to wt type amino acid coding (131). Similarly, the G98D mutant of IBV nsp9 significantly destabilized homodimer and also abolished the activity of RNA binding. The incorporated viral mutant was deficient in subgenomic RNAs transcription as well as viral growth. Interestingly, IBV nsp9 mutation I95N showed almost no effect on the RNA binding activity but moderately destabilized dimer formation, while the virus with this mutation has severe growth defects(132). Nsp9 dimerization may have essential roles in replication beyond the RNA binding.

\section{Nsp10: cofactor in viral replication}

Nsp10 is a zinc finger protein that contains two zinc finger domains conserved among coronaviruses (49, 50, 133). Several oligomer forms were reported for nsp10. MHV nsp10 shows the monomeric form in reducing SDSPAGE and gel filtration analysis. At the same time, it also forms $\sim 80 \mathrm{kDa}$ and $\sim 19600 \mathrm{kDa}$ protein complexes when supplemented with zinc ions in dynamic light scattering assay (133). SARS-CoV nsp10 was reported to form a dimer in solution analyzed by gel filtration (50). A simultaneous report on SARS-CoV nsp10 also revealed a dodecameric structure (49). Currently, no evidence confirmed the biological relevance of nsp 10 oligomerization in viral replication.

Nsp10 is essential to coronavirus infection. A temperature-sensitive mutation of nsp10 (Q65E) significantly inhibited MHV RNA synthesis at the nonpermissive temperature (134). Furthermore, the reverse-genetics study identified 16 nsp10 mutants of MHV clone, of which eight were viable but displayed attenuated viral growth, while the other eight clones were inviable (135). One of the nsp10 mutant (D47A/H48A) was studied into depth and had subtle effects on nsp410/11 polyprotein processing.

During viral replication, nsp10 enhances the enzyme activities of other replication proteins (136-138). SARS$\mathrm{CoV}$ nsp10 interacts with the exoribonuclease domain of nsp14, resulting in significantly increased exoribonuclease activity (136). Mutations on MHV nsp10 (R80A/E82A) led to increased sensitivity of the virus towards RNA mutagen treatments (25), suggestive of the involvement of nsp10 in coronavirus proof-reading function, which relies on the exoribonuclease activity of nsp14. A heterodimer complex structure was also identified for nsp10/nsp16 (137). Nsp10 interacts with the nsp16 S-adenosyl-L-methionine (SAM)-binding pocket and stimulates the association of both the methyl donor SAM and capped RNA acceptor to nsp16 (137), thus activates nsp16 to methylate coronaviral mRNA cap at the 2'O-site (139).

In addition to the role as a part of viral TRCs, nsp10 is involved in the development of viral cytopathic effects. SARS-CoV nsp10 interacts with human NADH 4L subunit and cytochrome oxidase II and alters the activity of the NADH-cytochrome (140). Through these interactions, 
nsp10 caused an impaired oxidoreductase system and induced the depolarization of the mitochondria inner membrane (140).

\section{Nsp11: small peptide with unknown function}

Nsp11 is a small peptide located at the C-terminus of ORF1a. A three-stemmed mRNA pseudoknot containing a typical hepta-nucleotide sequence UUUAAAC is situated in the nsp11 coding region (141). This RNA structure results in a programmed -1 ribosomal frameshift, which leads to the production of ORF1ab $(141,142)$.

A proximity-labeling experiment identified the existence of nearly all nonstructural proteins in the microenvironment of MHV replication complexes, except for nsp11 (128). SARS-CoV nsp11 does not interact with other nonstructural proteins in the mammalian two-hybrid assay (124). Currently, no known function was discovered for nsp11. According to these data, nsp11 is likely not a member of the replication complexes. However, the exact role of nsp11 remains to be explored.

\section{Nsp12: the main RdRp}

Nsp12 is the first nonstructural protein encoded by ORF $1 b$ and functions as the primary RNA-dependent RNA polymerase of coronaviruses. Nsp12 is at the center of the viral TRCs, which participate in both the synthesis of new full-length genomic RNA and the discontinuous transcription of subgenomic RNAs (18, 143-146).

Coronavirus nsp12 mainly contains two functional domains. The C-terminal portion of nsp12 is the canonical $\mathrm{RdRp}$ domain that resembles a cupped right hand with fingers, palm, and the thumb holding the template RNA $(44,147)$. The palm subdomain is the catalytic core that contains a conserved SDD motif in the active site. Like other positive-strand RNA viruses, mutations on the SDD motif abolished its RdRp activity (148). Asides from the C-terminal polymerase domain, nsp12 also contains a Nidovirus RdRp-associated nucleotidyltransferase (NiRAN) domain, which is unique to the Nidovirales $(44,147)$. The arterivirus equine arteritis virus (EAV) nsp9 is the homolog of coronaviruses nsp12. The NiRAN domain of EAV nsp9 can be nucleotidylated, as a phosphoamide bond can be formed in between the protein and a GTP or UTP molecule (149). Single-particle cryo-EM imaging shows a structure where the NiRAN domain of nsp12 interacts with an $n s p 7+n s p 8$ heterodimer as well as a second nsp8 (44). The interaction with nsp7 and nsp8 cofactors seems to help stabilize the nsp12 RNA binding region as well as extending the RNA-binding surface (44). Genetic studies also supported the essential role of this nucleotidylating activity of nsp12 in EAV and SARSCoV replication (149); however, the exact function of this activity is still unknown.

The SARS-CoV nsp12 RdRp activity was investigated after the outbreak of the SARS epidemic in 2002-2003 by several groups. Early studies using recombinant nsp12 showed a primer-dependent RNA polymerase activity $(118,119,150)$. This primer-dependent RdRp activity of nsp12 was proposed to work with the nsp 8 primase for the viral genome synthesis $(118,150)$. However, biochemical data of nsp8 lacking the de novo initiation RNA synthesis activity could not fill the gap in virus replication cycles, as to how the virus maintains its 5 '-end can not be explained. The biochemical assay by using recombinant nsp12 and nsp7/nsp8 cofactors showed de novo initiation ability of nsp12 (119), while the nsp8 primase activity could not be detected. Cryo-EM structure of this complex supported the de novo initiation activity for the nsp12 polymerase. This structure clearly showed that the active site of the nsp 8 primase could not fit into the nsp12 RNA synthesis pocket (44), further confirmed the biochemical finding that nsp8 does not have primase activity.

\section{Nsp13: the helicase}

Helicases are the enzymes that unwind double-stranded DNAs or RNAs $(151,152)$. RNA viruses encode RNA helicases (153) or recruit host alternatives (154-156) to promote their genome replication and viral gene expression. Apart from the "pro-viral" functions, RNA helicases are also involved in host antiviral responses (157). Explicitly, both animal and plant host innate immune systems encode RNA helicases to recognize and respond to foreign double-stranded RNA in the cytoplasm (157-160).

Coronavirus nsp13 encodes a C-terminal helicase domain that belongs to the superfamily one helicases (152). While at the $\mathrm{N}$-terminus of nsp13 is a zinc-binding domain (ZBD), which is conserved among the members in Nidovirales $(142,161,162)$. Nsp13 exhibits both RNA and DNA duplex unwinding activities in vitro shown by the biochemical study of recombinant nsp13 from HCoV229E $(163,164)$ and SARS-CoV $(165,166)$. Nsp13 unwinds its substrates in a 5'- 3' direction by using the energy generated from NTPs and dNTPs hydrolysis, with the most effectivity towards ATP, dATP, and GTP. Transient kinetic analysis showed that SARS-CoV nsp13 unwinds nucleic acid in discrete steps of $9.3 \mathrm{bp}$ each, with a catalytic rate of 30 steps per second (167). Moreover, the unwinding activity can be enhanced 2-fold by nsp12 through nsp12-nsp13 interaction (167). Nsp13 preferentially binds to 5 '-overhang and processes the double-strand with higher activity (168). ZBD is essential for helicase activity, and replacement of conserved ZBD Cys and His residues disrupted ATPase activities of HCoV-229E nsp13 (161). In addition to NTPase and dNTPase activities, RNA 5'-triphosphatase activity was discovered for HCoV-229E and SARS-CoV nsp13, which may catalyze the first step in the formation of the 5'-cap structure of viral RNAs $(164,165)$. The NTPase activity of arterivirus nsp10, the homolog of coronavirus nsp13, is essential to the viral survival (169). While mutation (A335V) on the RNA binding channel of MHV nsp13 conferred decreased viral replication both in vitro and in vivo (170).

\section{Nsp14: dual-functional RNA modifier}

The CoV nsp14 has dual functions in viral RNA processing (142). The N-terminus of nsp14 is a 3 ' -5 ' exonuclease (ExoN) (19). Nsp14 ExoN belongs to the 
DEDD superfamily of exonucleases. The exonuclease activity that acts on both ssRNA and dsRNA, but can not hydrolyze DNA or ribose- 2'-O-methylated RNA substrates in vitro (171). The ExoN activity can be stimulated to $>35$ fold by interacting with nsp10, and this complex can release one mismatched nucleotide from the 3'-end of the newly synthesized RNA strand (172). Coronavirus nsp14 ExoN activity is involved in the RNA proofreading machinery during viral replication. Mutant MHV or SARS-CoV with deficient ExoN activity displays a higher mutation rate and lower replication fidelity $(173,174)$. Moreover, ExoN is related to the host innate immune response. MHV lacking ExoN activity showed increased sensitivity to cellular pretreatment with IFN- $\beta$ (175). On the contrary, TGEV nsp14 probably is responsible for the induction of IFN- $\beta$ production through interaction with cellular RNA helicase DDX1 (176).

The C-terminus of nsp14 encodes for the guanosine N7-methyltransferase activity (177). When SARSCoV or TGEV nsp14 was overexpressed in yeast null mutant of mRNA guanine 7-methyltransferase $a b d 1$, the growth-deficient phenotype was restored (177). The nsp14 specifically methylates GTP, dGTP, or the inverted guanosine molecule attached to the 5'-end of RNA (178). When a point mutation at the MTase domain (D331A) was incorporated into SARS-CoV replicon carrying a luciferase reporter, the luciferase activity dropped to $10 \%$, and the subgenomic RNA accumulation dropped to $19 \%$ of the wt level (177). The defect in viral transcription and gene expression is likely due to the unstable viral RNA produced by the virus.

\section{Nsp15: endoribonuclease}

Nsp15 is a uridine-specific endoribonuclease (EndoU) that processes RNA in the viral replication/transcription complex (RTC) (31). It is a signature molecular marker for vertebrate Nidovirales $(179,180)$, as insect nidoviruses and viruses outside the Nidovirales do not encode such endoribonuclease $(19,181-183)$.

Nsp15 forms a hexamer $(46,48,184)$ that depends on manganese as a cofactor for its ribonuclease activity (185-187). Nsp15 can process both ssRNA and dsRNA, but not DNA (185). Blocking the 5'- or the 3'- ends of substrate RNAs did not prevent the RNA degradation, suggestive of the activity is mainly towards the middle (endo) portion of the RNA substrate $(185,188)$. A mass spectrometry analysis of SARS-CoV nsp 15 digested RNA products revealed that the major RNA cleavage site is the 3' of the uridylate. The 3' of cytidylate in favored sequence contexts can also be the site for cleavage (189). The hexamer form of SARS-CoV nsp15 was found to be responsible for RNA binding (189). Other studies on MHV nsp15 showed a higher binding affinity to RNA and similar ribonuclease activity of the monomer form (47).

Early genetic attempts using mutations of the vital amino acids in the MHV nsp15 catalytic pocket found that nsp15 deficient caused decreased RNA replication and viral growth in cell culture (190). Breakthrough in understanding its unique function was made a decade later by testing viral replication in mouse macrophages and in vivo $(24,191)$. The nsp15 EndoU-deficient mutant MHV stimulated an early induction of cytosolic dsRNA during infection, led to robust induction of IFN-I and PKR-mediated apoptosis, and exhibited impaired viral growth $(24,191)$. Moreover, the infection of the mutant virus was restricted in primary cells in vivo and could not efficiently spread (24). Thus the endoribonuclease activity of nsp15 promotes digestion of excessive viral dsRNAs at the replication sites and mediates viral evasion of host dsRNA-mediated innate immunity at the early stage of infection (186).

\section{Nsp16: 2'-O-methyltransferase}

Nsp16 encodes 2'-O-methyltransferase, which can methylate the RNA cap at ribose 2'-O positions resulting in a cap-1 structure (192). The 2'-O-MTase activity was predicted for SARS-CoV nsp16 by 3D modeling soon after the SARS epidemic in 2003 (192). However, the 2'-O-MTase activity was first demonstrated for FCoV nsp16 (193). On the contrary, SARS-CoV nsp16 along is inactive. It requires nsp10 as a cofactor to bind to SAM and m7GpppA-RNA substrate (137) and depends on nsp10 for its 2'-O-MTase activity (139). The crystal structure of SARS-CoV nsp 16 posts a non-canonical SAM-dependent 2'-O-MTase structure lacking two out of seven $\alpha$-helices, which may explain the requirements of nsp10 for its activity $(60,137)$.

SARS-CoV or MERS-CoV nsp16 mutants that contain mutations on conserved KDKE motif strongly attenuated viral infection in vitro and in vivo $(34,194)$. As common strategies among various RNA viruses to counteract innate immunity (192), the cap-1 type of modification help coronavirus evade the RNA recognition machinery and the antiviral responses mediated by IFN-I $(34,194)$. Viruses defective in the 2'-O-MTase activity showed increased sensitivity to IFN-I treatment comparing to the wt virus $(34,194)$. Host cytoplasmic RNA sensor Mda5 was shown to recognize those viral transcripts produced by the nsp 16 mutant virus, as in the absence of Mda5, the replication and virulence of the mutant virus was restored $(34,194)$.

\section{Nonstructural proteins are useful drug targets}

Phylogenetic studies and serological evidence shows that the human-infecting betacoronaviruses, including highly pathogenic SARS-CoV, SARS-CoV-2, and MERS-CoV, have animal origins $(9,63,195-197)$. Bats are identified as the natural reservoirs for human coronaviruses (198200). Bats usually do not display signs of disease when infected with coronaviruses and have evolved an immune system that allows virus propagation $(201,202)$. Due to the increasing human activities and global warming that result in the changing of bat habitats, the emergency of new zoonotic coronaviral diseases are very likely to occur (199-201). This consensus demands the development of novel anticoronaviral medicines. The nonstructural proteins or the viral replication processes of coronaviruses have been shown as potential antiviral drug targets (203). 
During the epidemic of SARS in 2003, structure simulation of SARS-CoV nsp5 3CL ${ }^{\text {pro }}$ suggested that the nsp5 substrate-binding sites are conserved with rhinovirus $3 \mathrm{C}^{\text {pro }}$ and can be targeted with the antirhinoviral drug AG7088 (204). Although AG7088 was soon demonstrated to be ineffective in inhibiting SARS-CoV replication (205), the HIV protease inhibitor lopinavir-ritonavir showed broad-spectrum antiviral activity targeting SARS-CoV, MERS-CoV 3CL ${ }^{\text {pro }}$, HCoV-229E, and HCoV-NL63 (64, 206-212). Immediately after the COVID-19 outbreak, several clinical studies for the use of protease inhibitors, such as lopinavir-ritonavir, darunavir-cobicistat, and ASC09F were started $(213,214)$. Unfortunately, one recently finished clinical trial showed that lopinavirritonavir treatment provides no therapeutic benefit to hospitalized severe COVID-19 adult patients (215). Similar to nsp5 $3 \mathrm{CL}^{\text {pro }}$, the $\mathrm{PL}^{\text {pro }}$ domain of nsp3 is also a drug target (216-218). Among the $\mathrm{PL}^{\text {pro }}$ inhibitors, disulfiram is clinically available for chronic alcohol dependence relief (216).

The coronaviral nsp12 RdRp serves as an important drug target. Nucleotide analogs can directly compete with nucleotide substrates of RdRp, resulting in the halt of the reaction as well as disruption of the viral replication (147). A recent report showed that remdesivir, an adenosine analog, can efficiently inhibit viral infection in SARSCoV-2 sensitive Huh-7 cell (219). The first SARS-CoV-2 patient in the United States administered remdesivir under the protocol of "compassionate use" and showed improved clinical conditions in about 24 hours and finally discharged from hospital, suggestive of a possible efficacy of remdesivir against coronavirus in this individual case (8). The uses of remdesivir and several other RdRp inhibitors for the treatment of COVID-19 are currently in clinical trials $(213,214)$.

Helicase domain of nsp13 also showed promise as a potential target. SSYA10-001, a 1,2,4-triazole derivative, can block the unwinding activity of nsp13 in a non-competitive manner (220), while myricetin and scutellarein suppress the ATPase activity of nsp13 (221). Furthermore, the adamantane-derived bananins can inhibit both ATPase and helicase activity of nsp13 and cause decreased viral infection in cell culture (222). However, none of these drug candidates went to clinical trials by the end of February 2020 (214).

\section{Summary}

Significant progress has been made in the understanding of the coronavirus nonstructural proteins, especially after the SARS epidemic in 2003. Most of the studies utilized cultured cells to investigate coronaviral infection, but the transgenic humanized mouse model also played critical roles in dissecting viral pathogenesis as well as aiding drug discoveries (223-225). These studies of coronaviral nonstructural proteins provided in-depth knowledge of how the viruses establish their infection and will continue to aid the discovery of new drugs effectively against coronaviruses.

\section{Acknowledgements}

The authors thank Dr. Zhenghe Li (Zhejiang University, China), Ms. Jiaojiao Zhang, Mr. Wang Zhang, Ms. Lingyun Zhou, and Ms. Ruoning Jin for the critical reading of the manuscript. This work was supported by the National Natural Science Foundation of China (31770164), Natural Science Foundation of Jiangsu Province (BK20180039), the Program for Jiangsu Excellent Scientific and Technological Innovation Team (17CXTD00014), and the Priority Academic Program Development (PAPD) of Jiangsu Higher Education Institutions.

\section{Conflict of interest}

The authors declare no conflict of interest concerning this review.

\section{References}

1. Cyranoski D. China joins investigation of mystery pneumonia. Nature. 2003;422(6931):459.

2. Pearson $\mathrm{H}$. Mystery virus slow to yield its identity as patient numbers rise. Nature. 2003;422(6930):364.

3. Assiri A, McGeer A, Perl TM, Price CS, Al Rabeeah AA, Cummings DA, et al. Hospital outbreak of Middle East respiratory syndrome coronavirus. N Engl J Med. 2013;369(5):407-16.

4. Zaki AM, van Boheemen S, Bestebroer TM, Osterhaus $A D$, Fouchier RA. Isolation of a novel coronavirus from a man with pneumonia in Saudi Arabia. N Engl J Med. 2012;367(19):1814-20.

5. Zhu N, Zhang D, Wang W, Li X, Yang B, Song J, et al. A Novel Coronavirus from Patients with Pneumonia in China, 2019. N Engl J Med. 2020;382(8):727-33.

6. Wang C, Horby PW, Hayden FG, Gao GF. A novel coronavirus outbreak of global health concern. Lancet. 2020;395(10223):470-3.

7. Lu R, Zhao X, Li J, Niu P, Yang B, Wu H, et al. Genomic characterisation and epidemiology of 2019 novel coronavirus: implications for virus origins and receptor binding. Lancet. 2020;395(10224):565-74.

8. Holshue ML, DeBolt C, Lindquist S, Lofy KH, Wiesman J, Bruce $\mathrm{H}$, et al. First Case of 2019 Novel Coronavirus in the United States. N Engl J Med. 2020;382(10):929-36.

9. Zhou P, Yang XL, Wang XG, Hu B, Zhang L, Zhang W, et al. A pneumonia outbreak associated with a new coronavirus of probable bat origin. Nature. 2020.

10. International Committee on Taxonomy of Viruses., King $A M Q$. Virus taxonomy : classification and nomenclature of viruses : ninth report of the International Committee on Taxonomy of Viruses. London ; Waltham, MA: Academic Press; 2012. x, 1327 p. p.

11. Pene F, Merlat A, Vabret A, Rozenberg F, Buzyn A, Dreyfus F, et al. Coronavirus 229E-related pneumonia in immunocompromised patients. Clin Infect Dis. 2003;37(7):929-32.

12. van der Hoek L, Pyrc K, Jebbink MF, Vermeulen-Oost W, Berkhout RJ, Wolthers KC, et al. Identification of a new human coronavirus. Nat Med. 2004;10(4):368-73.

13. Lau SK, Lee $P$, Tsang AK, Yip CC, Tse H, Lee RA, et al. Molecular epidemiology of human coronavirus $\mathrm{OC} 43$ reveals evolution of different genotypes over time and recent emergence of a novel genotype due to natural recombination. J Virol. 2011;85(21):11325-37.

14. Woo PC, Lau SK, Chu CM, Chan KH, Tsoi HW, Huang Y, et al. Characterization and complete genome sequence of a novel coronavirus, coronavirus HKU1, from patients with pneumonia. J Virol. 2005;79(2):884-95.

15. Marra MA, Jones SJ, Astell CR, Holt RA, Brooks-Wilson A, Butterfield YS, et al. The Genome sequence of the SARSassociated coronavirus. Science. 2003;300(5624):1399-404.

16. Coronaviridae Study Group of the International Committee on Taxonomy of $\mathrm{V}$. The species Severe acute respiratory 
syndrome-related coronavirus: classifying 2019-nCoV and naming it SARS-CoV-2. Nat Microbiol. 2020 Mar 2. [Epub ahead of print]

17. Masters PS. The molecular biology of coronaviruses. Adv Virus Res. 2006;66:193-292.

18. Fehr AR, Perlman S. Coronaviruses: an overview of their replication and pathogenesis. Methods Mol Biol. 2015;1282:1-23.

19. Lauber C, Goeman JJ, Parquet Mdel C, Nga PT, Snijder EJ, Morita K, et al. The footprint of genome architecture in the largest genome expansion in RNA viruses. PLoS Pathog. 2013;9(7):e1003500.

20. Wu A, Peng $Y$, Huang $B$, Ding $X$, Wang $X$, Niu $P$, et al.Genome composition and divergence of the novel coronavirus (2019-nCoV) originating in China. Cell Host Microbe. 2020 Mar 11;27(3):325-28.

21. Yang $X$, Chen X, Bian G, Tu J, Xing $Y$, Wang $Y$, et al. Proteolytic processing, deubiquitinase and interferon antagonist activities of Middle East respiratory syndrome coronavirus papain-like protease. J Gen Virol. 2014;95(Pt 3):614-26.

22. Lin PY, Chou CY, Chang HC, Hsu WC, Chang GG Correlation between dissociation and catalysis of SARS-CoV main protease. Arch Biochem Biophys. 2008;472(1):34-42.

23. van Hemert MJ, van den Worm SH, Knoops K, Mommaas AM, Gorbalenya AE, Snijder EJ. SARS-coronavirus replication/transcription complexes are membrane-protected and need a host factor for activity in vitro. PLoS Pathog. 2008;4(5):e1000054.

24. Kindler E, Gil-Cruz C, Spanier J, Li Y, Wilhelm J, Rabouw $\mathrm{HH}$, et al. Early endonuclease-mediated evasion of RNA sensing ensures efficient coronavirus replication. PLoS Pathog. 2017;13(2):e1006195.

25. Smith EC, Case JB, Blanc $\mathrm{H}$, Isakov O, Shomron $\mathrm{N}$, Vignuzzi $\mathrm{M}$, et al. Mutations in coronavirus nonstructural protein 10 decrease virus replication fidelity. J Virol. 2015;89(12):6418-26.

26. Zhai Y, Sun F, Li X, Pang H, Xu X, Bartlam M, et al. Insights into SARS-CoV transcription and replication from the structure of the nsp7-nsp8 hexadecamer. Nat Struct Mol Biol. 2005;12(11):980-6.

27. Sparks JS, Lu X, Denison MR. Genetic analysis of Murine hepatitis virus nsp4 in virus replication. J Virol. 2007;81(22):12554-63.

28. Knoops K, Kikkert M, Worm SH, Zevenhoven-Dobbe JC, van der Meer Y, Koster AJ, et al. SARS-coronavirus replication is supported by a reticulovesicular network of modified endoplasmic reticulum. PLoS Biol. 2008;6(9):e226.

29. Fehr AR, Jankevicius G, Ahel I, Perlman S. Viral Macrodomains: Unique Mediators of Viral Replication and Pathogenesis. Trends Microbiol. 2018;26(7):598-610.

30. Graham RL, Sims AC, Brockway SM, Baric RS Denison MR. The nsp2 replicase proteins of murine hepatitis virus and severe acute respiratory syndrome coronavirus are dispensable for viral replication. J Virol. 2005;79(21):13399-411.

31. Athmer J, Fehr AR, Grunewald M, Smith EC, Denison MR, Perlman S. In Situ Tagged nsp15 Reveals Interactions with Coronavirus Replication/Transcription Complex-Associated Proteins. mBio. 2017;8(1).

32. Kusov Y, Tan J, Alvarez E, Enjuanes L, Hilgenfeld R. A G-quadruplex-binding macrodomain within the "SARSunique domain" is essential for the activity of the SARS coronavirus replication-transcription complex. Virology. 2015:484:313-22.

33. Imbert I, Snijder EJ, Dimitrova M, Guillemot JC, Lecine P, Canard B. The SARS-Coronavirus PLnc domain of nsp3 as a replication/transcription scaffolding protein. Virus Res. 2008;133(2):136-48.

34. Menachery VD, Gralinski LE, Mitchell HD, Dinnon KH, 3rd, Leist SR, Yount BL, Jr., et al. Middle East Respiratory
Syndrome Coronavirus Nonstructural Protein 16 Is Necessary for Interferon Resistance and Viral Pathogenesis. mSphere. 2017;2(6).

35. Alfuwaires M, Altaher A, Kandeel M. Molecular Dynamic Studies of Interferon and Innate Immunity Resistance in MERS CoV Non-Structural Protein 3. Biol Pharm Bull. 2017;40(3):345-51.

36. Fehr AR, Channappanavar R, Jankevicius G, Fett C, Zhao J, Athmer J, et al. The Conserved Coronavirus Macrodomain Promotes Virulence and Suppresses the Innate Immune Response during Severe Acute Respiratory Syndrome Coronavirus Infection. mBio. 2016;7(6).

37. Zhu X, Fang L, Wang D, Yang Y, Chen J, Ye X, et al. Porcine deltacoronavirus nsp5 inhibits interferon-beta production through the cleavage of NEMO. Virology. 2017;502:33-8.

38. Chen S, Tian J, Li Z, Kang H, Zhang J, Huang J, et al. Feline Infectious Peritonitis Virus Nsp5 Inhibits Type I Interferon Production by Cleaving NEMO at Multiple Sites. Viruses. 2019;12(1).

39. Zhu X, Wang D, Zhou J, Pan T, Chen J, Yang Y, et al. Porcine Deltacoronavirus nsp5 Antagonizes Type I Interferon Signaling by Cleaving STAT2. J Virol. 2017;91(10).

40. Yuan L, Chen Z, Song S, Wang S, Tian C, Xing G, et al. p53 degradation by a coronavirus papain-like protease suppresses type I interferon signaling. J Biol Chem. 2015;290(5):3172-82.

41. Clementz MA, Chen Z, Banach BS, Wang Y, Sun L, Ratia $\mathrm{K}$, et al. Deubiquitinating and interferon antagonism activities of coronavirus papain-like proteases. J Virol. 2010;84(9):4619-29.

42. Oostra M, Hagemeijer MC, van Gent M, Bekker CP, te Lintelo EG, Rottier PJ, et al. Topology and membrane anchoring of the coronavirus replication complex: not all hydrophobic domains of nsp 3 and nsp 6 are membrane spanning. J Virol. 2008;82(24):12392-405.

43. Hagemeijer MC, Verheije MH, Ulasli M, Shaltiel IA, de Vries LA, Reggiori F, et al. Dynamics of coronavirus replicationtranscription complexes. J Virol. 2010;84(4):2134-49.

44. Kirchdoerfer RN, Ward AB. Structure of the SARS-CoV nsp12 polymerase bound to nsp7 and nsp8 co-factors. Nat Commun. 2019;10(1):2342

45. Sutton G, Fry E, Carter L, Sainsbury S, Walter T, Nettleship J, et al. The nsp9 replicase protein of SARScoronavirus, structure and functional insights. Structure. 2004;12(2):341-53.

46. Joseph JS, Saikatendu KS, Subramanian V, Neuman BW, Buchmeier MJ, Stevens RC, et al. Crystal structure of a monomeric form of severe acute respiratory syndrome coronavirus endonuclease nsp15 suggests a role for hexamerization as an allosteric switch. J Virol. 2007;81(12):6700-8.

47. Xu X, Zhai Y, Sun F, Lou Z, Su D, Xu Y, et al. New antiviral target revealed by the hexameric structure of mouse hepatitis virus nonstructural protein nsp15. J Virol. 2006;80(16):7909-17.

48. Ricagno S, Egloff MP, Ulferts R, Coutard B, Nurizzo D, Campanacci $V$, et al. Crystal structure and mechanistic determinants of SARS coronavirus nonstructural protein 15 define an endoribonuclease family. Proc Natl Acad Sci U S A. 2006;103(32):11892-7.

49. Su D, Lou Z, Sun F, Zhai Y, Yang H, Zhang R, et al. Dodecamer structure of severe acute respiratory syndrome coronavirus nonstructural protein nsp10. J Virol. 2006;80(16):7902-8.

50. Joseph JS, Saikatendu KS, Subramanian V, Neuman BW, Brooun A, Griffith M, et al. Crystal structure of nonstructural protein 10 from the severe acute respiratory syndrome coronavirus reveals a novel fold with two zinc-binding motifs. J Virol. 2006;80(16):7894-901.

51. Hu T, Zhang Y, Li L, Wang K, Chen S, Chen J, et al. Two adjacent mutations on the dimer interface of SARS 
coronavirus 3C-like protease cause different conformational changes in crystal structure. Virology. 2009;388(2):324-34.

52. Serrano P, Johnson MA, Chatterjee A, Neuman BW, Joseph JS, Buchmeier MJ, et al. Nuclear magnetic resonance structure of the nucleic acid-binding domain of severe acute respiratory syndrome coronavirus nonstructural protein 3 . J Virol. 2009;83(24):12998-3008

53. Baez-Santos YM, St John SE, Mesecar AD. The SARScoronavirus papain-like protease: structure, function and inhibition by designed antiviral compounds. Antiviral Res. 2015;115:21-38.

54. Cho CC, Lin MH, Chuang $\mathrm{CY}$, Hsu CH. Macro domain from middle east respiratory syndrome coronavirus (MERSCoV)is an efficient ADP-ribose binding module: crysta structure and biochemical studies. J Biol Chem. 2016;291(10):4894-902.

55. Xu Y, Cong L, Chen C, Wei L, Zhao Q, Xu X, et al. Crystal structures of two coronavirus ADP-ribose-1"monophosphatases and their complexes with ADP-Ribose: a systematic structural analysis of the viral ADRP domain. J Virol. 2009;83(2):1083-92.

56. Piotrowski Y, Hansen G, Boomaars-van der Zanden AL, Snijder EJ, Gorbalenya AE, Hilgenfeld R. Crystal structures of the X-domains of a Group-1 and a Group-3 coronavirus reveal that $A D P$-ribose-binding may not be a conserved property. Protein Sci. 2009;18(1):6-16.

57. Keane SC, Giedroc DP. Solution structure of mouse hepatitis virus (MHV) nsp3a and determinants of the interaction with MHV nucleocapsid (N) protein. J Virol. 2013;87(6):3502-15.

58. Serrano $P$, Johnson MA, Almeida MS, Horst R, Herrmann $\mathrm{T}$, Joseph JS, et al. Nuclear magnetic resonance structure of the $\mathrm{N}$-terminal domain of nonstructural protein 3 from the severe acute respiratory syndrome coronavirus. J Virol. 2007;81(21):12049-60.

59. Han W, Li X, Fu X. The macro domain protein family: structure, functions, and their potential therapeutic implications. Mutat Res. 2011;727(3):86-103.

60. Subissi L, Imbert I, Ferron F, Collet A, Coutard B, Decroly E, et al. SARS-CoV ORF1b-encoded nonstructural proteins 1216: replicative enzymes as antiviral targets. Antiviral Res. 2014;101:122-30

61. Lundin A, Dijkman R, Bergstrom T, Kann N, Adamiak B, Hannoun C, et al. Targeting membrane-bound viral RNA synthesis reveals potent inhibition of diverse coronaviruses including the middle East respiratory syndrome virus. PLoS Pathog. 2014;10(5):e1004166.

62. Pfefferle S, Schopf J, Kogl M, Friedel CC, Muller MA Carbajo-Lozoya J, et al. The SARS-coronavirus-host interactome: identification of cyclophilins as target for pancoronavirus inhibitors. PLoS Pathog. 2011;7(10):e1002331.

63. Chan JF, Kok KH, Zhu Z, Chu H, To KK, Yuan S, et al. Genomic characterization of the 2019 novel humanpathogenic coronavirus isolated from a patient with atypica pneumonia after visiting Wuhan. Emerg Microbes Infect. 2020;9(1):221-36.

64. Kilianski A, Mielech AM, Deng X, Baker SC. Assessing activity and inhibition of Middle East respiratory syndrome coronavirus papain-like and $3 \mathrm{C}$-like proteases using luciferase-based biosensors. J Virol. 2013;87(21):11955-62.

65. Prentice E, McAuliffe J, Lu X, Subbarao K, Denison $M R$. Identification and characterization of severe acute respiratory syndrome coronavirus replicase proteins. J Virol. 2004;78(18):9977-86

66. Kamitani W, Narayanan K, Huang C, Lokugamage K, Ikegami $\mathrm{T}$, Ito $\mathrm{N}$, et al. Severe acute respiratory syndrome coronavirus nsp1 protein suppresses host gene expression by promoting host mRNA degradation. Proc Natl Acad Sci U S A. 2006;103(34):12885-90.

67. Zust R, Cervantes-Barragan L, Kuri T, Blakqori G, Weber $\mathrm{F}$, Ludewig B, et al. Coronavirus non-structural protein 1 is a major pathogenicity factor: implications for the rational design of coronavirus vaccines. PLoS Pathog. 2007;3(8):e109.

68. Tohya Y, Narayanan K, Kamitani W, Huang C, Lokugamage $\mathrm{K}$, Makino S. Suppression of host gene expression by nsp1 proteins of group 2 bat coronaviruses. J Virol. 2009;83(10):5282-8.

69. Kamitani W, Huang C, Narayanan K, Lokugamage KG, Makino S. A two-pronged strategy to suppress host protein synthesis by SARS coronavirus Nsp1 protein. Nat Struct Mol Biol. 2009;16(11):1134-40.

70. Huang C, Lokugamage KG, Rozovics JM, Narayanan K, Semler BL, Makino S. SARS coronavirus nsp1 protein induces template-dependent endonucleolytic cleavage of mRNAs: viral mRNAs are resistant to nsp1-induced RNA cleavage. PLoS Pathog. 2011;7(12):e1002433.

71. Gaglia MM, Covarrubias S, Wong W, Glaunsinger BA. A common strategy for host RNA degradation by divergent viruses. J Virol. 2012;86(17):9527-30.

72. Tanaka T, Kamitani W, DeDiego ML, Enjuanes L, Matsuura Y. Severe acute respiratory syndrome coronavirus nsp1 facilitates efficient propagation in cells through a specific translational shutoff of host mRNA. J Virol. 2012;86(20):11128-37.

73. Terada Y, Kawachi K, Matsuura Y, Kamitani W. MERS coronavirus nsp1 participates in an efficient propagation through a specific interaction with viral RNA. Virology. 2017;511:95-105.

74. Menachery VD, Graham RL, Baric RS. Jumping species-a mechanism for coronavirus persistence and survival. Curr Opin Virol. 2017;23:1-7

75. Graham RL, Sims AC, Baric RS, Denison MR. The nsp2 proteins of mouse hepatitis virus and SARS coronavirus are dispensable for viral replication. Adv Exp Med Biol. 2006;581:67-72

76. Gadlage MJ, Graham RL, Denison MR. Murine coronaviruses encoding nsp2 at different genomic loci have altered replication, protein expression, and localization. J Virol. 2008;82(23):11964-9.

77. Angelini MM, Akhlaghpour M, Neuman BW, Buchmeier MJ. Severe acute respiratory syndrome coronavirus nonstructural proteins 3,4 , and 6 induce double-membrane vesicles. mBio. 2013;4(4).

78. Hagemeijer MC, Monastyrska I, Griffith J, van der Sluijs P, Voortman J, van Bergen en Henegouwen PM, et al. Membrane rearrangements mediated by coronavirus nonstructural proteins 3 and 4. Virology. 2014;458-459:125-35.

79. Hurst KR, Koetzner CA, Masters PS. Characterization of a critical interaction between the coronavirus nucleocapsid protein and nonstructural protein 3 of the viral replicasetranscriptase complex. J Virol. 2013;87(16):9159-72.

80. Hurst KR, Ye R, Goebel SJ, Jayaraman P, Masters PS. An interaction between the nucleocapsid protein and a component of the replicase-transcriptase complex is crucial for the infectivity of coronavirus genomic RNA. J Virol. 2010;84(19):10276-88.

81. Fehr AR, Athmer J, Channappanavar R, Phillips JM Meyerholz DK, Perlman S. The nsp3 macrodomain promotes virulence in mice with coronavirus-induced encephalitis. J Virol. 2015;89(3):1523-36.

82. Lei J, Kusov Y, Hilgenfeld R. Nsp3 of coronaviruses: Structures and functions of a large multi-domain protein. Antiviral Res. 2018;149:58-74.

83. Davis ME, Gack MU. Ubiquitination in the antiviral immune response. Virology. 2015;479-480:52-65.

84. Heaton SM, Borg NA, Dixit VM. Ubiquitin in the activation and attenuation of innate antiviral immunity. J Exp Med. 2016;213(1):1-13.

85. Morales DJ, Lenschow DJ. The antiviral activities of ISG15. J Mol Biol. 2013;425(24):4995-5008.

86. Perng YC, Lenschow DJ. ISG15 in antiviral immunity and beyond. Nat Rev Microbiol. 2018;16(7):423-39. 
87. Koonin EV, Gorbalenya AE, Purdy MA, Rozanov MN, Reyes GR, Bradley DW. Computer-assisted assignment of functional domains in the nonstructural polyprotein of hepatitis $E$ virus: delineation of an additional group of positive-strand RNA plant and animal viruses. Proc Natl Acad Sci U S A. 1992;89(17):8259-63.

88. Gorbalenya AE, Koonin EV, Lai MM. Putative papain-related thiol proteases of positive-strand RNA viruses. Identification of rubi- and aphthovirus proteases and delineation of a nove conserved domain associated with proteases of rubi-, alphaand coronaviruses. FEBS Lett. 1991;288(1-2):201-5.

89. Dominguez G, Wang CY, Frey TK. Sequence of the genome RNA of rubella virus: evidence for genetic rearrangement during togavirus evolution. Virology. 1990;177(1):225-38.

90. Saikatendu KS, Joseph JS, Subramanian V, Clayton T, Griffith M, Moy K, et al. Structural basis of severe acute respiratory syndrome coronavirus ADP-ribose-1"-phosphate dephosphorylation by a conserved domain of nsP3. Structure. 2005;13(11):1665-75.

91. Egloff MP, Malet $H$, Putics A, Heinonen M, Dutartre $H$, Frangeul A, et al. Structural and functional basis for ADPribose and poly(ADP-ribose) binding by viral macro domains. J Virol. 2006;80(17):8493-502.

92. Costanzi C, Pehrson JR. Histone macroH2A1 is concentrated in the inactive $X$ chromosome of female mammals. Nature. 1998;393(6685):599-601.

93. Li C, Debing Y, Jankevicius G, Neyts J, Ahel I, Coutard B, et al. Viral Macro Domains Reverse Protein ADP-Ribosylation. J Virol. 2016;90(19):8478-86.

94. Neuman BW. Bioinformatics and functional analyses of coronavirus nonstructural proteins involved in the formation of replicative organelles. Antiviral Res. 2016;135:97-107.

95. Johnson MA, Chatterjee A, Neuman BW, Wuthrich K SARS coronavirus unique domain: three-domain molecular architecture in solution and RNA binding. J Mol Biol. 2010;400(4):724-42.

96. Tan J, Kusov Y, Mutschall D, Tech S, Nagarajan K, Hilgenfeld R, et al. The "SARS-unique domain" (SUD) of SARS coronavirus is an oligo(G)-binding protein. Biochem Biophys Res Commun. 2007;364(4):877-82.

97. Bencze KZ, Kondapalli KC, Cook JD, McMahon S, MillanPacheco C, Pastor N, et al. The structure and function of frataxin. Crit Rev Biochem Mol Biol. 2006;41(5):269-91.

98. Chen Y, Savinov SN, Mielech AM, Cao T, Baker SC, Mesecar AD. X-ray Structural and Functional Studies of the Three Tandemly Linked Domains of Non-structural Protein 3 (nsp3) from Murine Hepatitis Virus Reveal Conserved Functions. J Biol Chem. 2015;290(42):25293-306.

99. Frieman M, Ratia K, Johnston RE, Mesecar AD, Baric RS Severe acute respiratory syndrome coronavirus papain-like protease ubiquitin-like domain and catalytic domain regulate antagonism of IRF3 and NF-kappaB signaling. J Virol. 2009;83(13):6689-705.

100. Mielech AM, Kilianski A, Baez-Santos YM, Mesecar AD, Baker SC. MERS-CoV papain-like protease has delSGylating and deubiquitinating activities. Virology. 2014;450-451:64-70.

101. Lindner HA, Fotouhi-Ardakani N, Lytvyn V, Lachance $\mathrm{P}$, Sulea T, Menard R. The papain-like protease from the severe acute respiratory syndrome coronavirus is a deubiquitinating enzyme. J Virol. 2005;79(24):15199-208.

102. Barretto N, Jukneliene D, Ratia K, Chen Z, Mesecar $A D$, Baker SC. The papain-like protease of severe acute respiratory syndrome coronavirus has deubiquitinating activity. J Virol. 2005;79(24):15189-98.

103. Malynn BA, Ma A. Ubiquitin makes its mark on immune regulation. Immunity. 2010;33(6):843-52.

104. Tanaka Y, Chen ZJ. STING specifies IRF3 phosphorylation by TBK1 in the cytosolic DNA signaling pathway. Sci Signal. 2012;5(214):ra20.

105. Li SW, Wang CY, Jou YJ, Huang SH, Hsiao LH, Wan L, et al. SARS Coronavirus Papain-Like Protease Inhibits the TLR7 Signaling Pathway through Removing Lys63-Linked Polyubiquitination of TRAF3 and TRAF6. Int J Mol Sci. 2016;17(5).

106. Ma-Lauer Y, Carbajo-Lozoya J, Hein MY, Muller MA, Deng $W$, Lei J, et al. p53 down-regulates SARS coronavirus replication and is targeted by the SARS-unique domain and PLpro via E3 ubiquitin ligase RCHY1. Proc Natl Acad Sci U S A. 2016;113(35):E5192-201.

107. Oudshoorn D, Rijs K, Limpens R, Groen K, Koster AJ, Snijder EJ, et al. Expression and Cleavage of Middle East Respiratory Syndrome Coronavirus nsp3-4 Polyprotein Induce the Formation of Double-Membrane Vesicles That Mimic Those Associated with Coronaviral RNA Replication. mBio. 2017;8(6).

108. Gadlage MJ, Sparks JS, Beachboard DC, Cox RG, Doyle JD, Stobart CC, et al. Murine hepatitis virus nonstructural protein 4 regulates virus-induced membrane modifications and replication complex function. J Virol. 2010;84(1):280-90.

109. Sakai $Y$, Kawachi K, Terada $Y$, Omori H, Matsuura $Y$, Kamitani W. Two-amino acids change in the nsp4 of SARS coronavirus abolishes viral replication. Virology. 2017;510:165-74.

110. Zhang S, Zhong N, Xue F, Kang X, Ren X, Chen J, et al. Three-dimensional domain swapping as a mechanism to lock the active conformation in a super-active octamer of SARS-CoV main protease. Protein Cell. 2010;1(4):371-83.

111. Shi J, Sivaraman J, Song J. Mechanism for controlling the dimer-monomer switch and coupling dimerization to catalysis of the severe acute respiratory syndrome coronavirus 3C-like protease. J Virol. 2008;82(9):4620-9.

112. Fan K, Wei $P$, Feng $Q$, Chen $S$, Huang $C$, Ma $L$, et al. Biosynthesis, purification, and substrate specificity of severe acute respiratory syndrome coronavirus 3C-like proteinase. J Biol Chem. 2004;279(3):1637-42.

113. Cottam EM, Maier HJ, Manifava M, Vaux LC, ChandraSchoenfelder P, Gerner W, et al. Coronavirus nsp6 proteins generate autophagosomes from the endoplasmic reticulum via an omegasome intermediate. Autophagy. 2011;7(11):1335-47

114. Reggiori F, Monastyrska I, Verheije $\mathrm{MH}$, Cali T, Ulasli M, Bianchi S, et al. Coronaviruses Hijack the LC3-I-positive EDEMosomes, ER-derived vesicles exporting shortlived ERAD regulators, for replication. Cell Host Microbe. 2010;7(6):500-8

115. Zhao Z, Thackray LB, Miller BC, Lynn TM, Becker MM, Ward $E$, et al. Coronavirus replication does not require the autophagy gene ATG5. Autophagy. 2007;3(6):581-5

116. Deming DJ, Graham RL, Denison MR, Baric RS. Processing of open reading frame 1 a replicase proteins nsp7 to nsp10 in murine hepatitis virus strain A59 replication. J Virol. 2007;81(19):10280-91.

117. Imbert I, Guillemot JC, Bourhis JM, Bussetta C, Coutard $B$, Egloff MP, et al. A second, non-canonical RNAdependent RNA polymerase in SARS coronavirus. EMBO J. 2006;25(20):4933-42.

118. te Velthuis AJ, van den Worm SH, Snijder EJ. The SARScoronavirus nsp7+nsp8 complex is a unique multimeric RNA polymerase capable of both de novo initiation and primer extension. Nucleic Acids Res. 2012;40(4):1737-47.

119. Subissi L, Posthuma CC, Collet A, Zevenhoven-Dobbe JC, Gorbalenya AE, Decroly E, et al. One severe acute respiratory syndrome coronavirus protein complex integrates processive RNA polymerase and exonuclease activities. Proc Natl Acad Sci U S A. 2014;111(37):E3900-9.

120. Xiao $Y$, Ma Q, Restle T, Shang W, Svergun DI, Ponnusamy $\mathrm{R}$, et al. Nonstructural proteins 7 and 8 of feline coronavirus form a 2:1 heterotrimer that exhibits primer-independent RNA polymerase activity. J Virol. 2012;86(8):4444-54.

121. Li S, Zhao Q, Zhang Y, Zhang Y, Bartlam M, Li X, et al. New nsp8 isoform suggests mechanism for tuning viral RNA 
synthesis. Protein Cell. 2010;1(2):198-204.

122. Egloff MP, Ferron F, Campanacci V, Longhi S, Rancurel C Dutartre $\mathrm{H}$, et al. The severe acute respiratory syndromecoronavirus replicative protein nsp9 is a single-stranded RNA-binding subunit unique in the RNA virus world. Proc Natl Acad Sci U S A. 2004;101(11):3792-6.

123. Ponnusamy R, Moll R, Weimar T, Mesters JR, Hilgenfeld R. Variable oligomerization modes in coronavirus non-structural protein 9. J Mol Biol. 2008;383(5):1081-96.

124. Pan J, Peng X, Gao Y, Li Z, Lu X, Chen Y, et al. Genomewide analysis of protein-protein interactions and involvement of viral proteins in SARS-CoV replication. PLoS One. 2008;3(10):e3299.

125. Tan YW, Fung TS, Shen H, Huang M, Liu DX. Coronavirus infectious bronchitis virus non-structural proteins 8 and 12 form stable complex independent of the non-translated regions of viral RNA and other viral proteins. Virology. 2018;513:75-84.

126. von Brunn A, Teepe C, Simpson JC, Pepperkok R, Friedel $\mathrm{CC}$, Zimmer R, et al. Analysis of intraviral protein-protein interactions of the SARS coronavirus ORFeome. PLoS One. 2007;2(5):e459.

127. Bost AG, Carnahan RH, Lu XT, Denison MR. Four proteins processed from the replicase gene polyprotein of mouse hepatitis virus colocalize in the cell periphery and adjacent to sites of virion assembly. J Virol. 2000;74(7):3379-87.

128. V'Kovski P, Gerber M, Kelly J, Pfaender S, Ebert N, Braga Lagache $S$, et al. Determination of host proteins composing the microenvironment of coronavirus replicase complexes by proximity-labeling. Elife. 2019;8.

129. Zeng Z, Deng F, Shi K, Ye G, Wang G, Fang L, et al. Dimerization of Coronavirus nsp9 with Diverse Modes Enhances Its Nucleic Acid Binding Affinity. J Virol. 2018;92(17).

130. Hu T, Chen C, Li H, Dou Y, Zhou M, Lu D, et al. Structural basis for dimerization and RNA binding of avian infectious bronchitis virus nsp9. Protein Sci. 2017;26(5):1037-48.

131. Miknis ZJ, Donaldson EF, Umland TC, Rimmer RA, Baric RS, Schultz LW. Severe acute respiratory syndrome coronavirus nsp9 dimerization is essential for efficient viral growth. J Virol. 2009;83(7):3007-18.

132. Chen B, Fang S, Tam JP, Liu DX. Formation of stable homodimer via the $\mathrm{C}$-terminal alpha-helical domain of coronavirus nonstructural protein 9 is critical for its function in viral replication. Virology. 2009;383(2):328-37.

133. Matthes N, Mesters JR, Coutard B, Canard B, Snijder EJ, Moll R, et al. The non-structural protein Nsp10 of mouse hepatitis virus binds zinc ions and nucleic acids. FEBS Lett. 2006;580(17):4143-9.

134. Sawicki SG, Sawicki DL, Younker D, Meyer Y, Thiel $\mathrm{V}$, Stokes $\mathrm{H}$, et al. Functional and genetic analysis of coronavirus replicase-transcriptase proteins. PLoS Pathog. 2005;1(4):e39.

135. Donaldson EF, Sims AC, Graham RL, Denison MR, Baric RS. Murine hepatitis virus replicase protein nsp10 is a critical regulator of viral RNA synthesis. J Virol. 2007;81(12):6356-68.

136. Ma Y, Wu L, Shaw N, Gao Y, Wang J, Sun Y, et al. Structural basis and functional analysis of the SARS coronavirus nsp14-nsp10 complex. Proc Natl Acad Sci U S A 2015;112(30):9436-41.

137. Chen Y, Su C, Ke M, Jin X, Xu L, Zhang Z, et al. Biochemical and structural insights into the mechanisms of SARS coronavirus RNA ribose 2'-O-methylation by nsp16/nsp 10 protein complex. PLoS Pathog. 2011;7(10):e1002294.

138. Bouvet M, Lugari A, Posthuma CC, Zevenhoven JC, Bernard S, Betzi S, et al. Coronavirus Nsp10, a critical co-factor for activation of multiple replicative enzymes. J Biol Chem. 2014;289(37):25783-96.

139. Bouvet M, Debarnot C, Imbert I, Selisko B, Snijder EJ, Canard B, et al. In vitro reconstitution of SARS-coronavirus mRNA cap methylation. PLoS Pathog. 2010;6(4):e1000863.
140. Li Q, Wang L, Dong C, Che Y, Jiang L, Liu L, et al. The interaction of the SARS coronavirus non-structural protein 10 with the cellular oxido-reductase system causes an extensive cytopathic effect. J Clin Virol. 2005;34(2):133-9.

141. Plant EP, Perez-Alvarado GC, Jacobs JL, Mukhopadhyay B, Hennig M, Dinman JD. A three-stemmed mRNA pseudoknot in the SARS coronavirus frameshift signal. PLoS Biol. 2005;3(6):e172.

142. Sola I, Almazan F, Zuniga S, Enjuanes L. Continuous and Discontinuous RNA Synthesis in Coronaviruses. Annu Rev Virol. 2015;2(1):265-88.

143. Ziebuhr J, Snijder EJ, Gorbalenya AE. Virus-encoded proteinases and proteolytic processing in the Nidovirales. $J$ Gen Virol. 2000;81(Pt 4):853-79.

144. Ziebuhr J. The coronavirus replicase. Curr Top Microbiol Immunol. 2005;287:57-94.

145. Snijder EJ, Bredenbeek PJ, Dobbe JC, Thiel V, Ziebuhr $\mathrm{J}$, Poon LL, et al. Unique and conserved features of genome and proteome of SARS-coronavirus, an early split-off from the coronavirus group 2 lineage. J Mol Biol. 2003;331(5):991-1004.

146. Miller WA, Koev G. Synthesis of subgenomic RNAs by positive-strand RNA viruses. Virology. 2000;273(1):1-8.

147. Xu X, Liu Y, Weiss S, Arnold E, Sarafianos SG, Ding J. Molecular model of SARS coronavirus polymerase: implications for biochemical functions and drug design. Nucleic Acids Res. 2003:31(24):7117-30.

148. Ahn DG, Choi JK, Taylor DR, Oh JW. Biochemical characterization of a recombinant SARS coronavirus nsp12 RNA-dependent RNA polymerase capable of copying viral RNA templates. Arch Virol. 2012;157(11):2095-104.

149. Lehmann KC, Gulyaeva A, Zevenhoven-Dobbe JC, Janssen GM, Ruben M, Overkleeft HS, et al. Discovery of an essential nucleotidylating activity associated with a newly delineated conserved domain in the RNA polymerasecontaining protein of all nidoviruses. Nucleic Acids Res. 2015;43(17):8416-34.

150. te Velthuis AJ, Arnold JJ, Cameron CE, van den Worm $\mathrm{SH}$, Snijder EJ. The RNA polymerase activity of SARScoronavirus nsp12 is primer dependent. Nucleic Acids Res. 2010;38(1):203-14.

151. Ranji A, Boris-Lawrie K. RNA helicases: emerging roles in viral replication and the host innate response. RNA Biol. 2010;7(6):775-87.

152. Singleton MR, Dillingham MS, Wigley DB. Structure and mechanism of helicases and nucleic acid translocases. Annu Rev Biochem. 2007;76:23-50.

153. Kadare G, Haenni AL. Virus-encoded RNA helicases. J Virol. 1997;71(4):2583-90.

154. Wang Y, Chen X, Xie J, Zhou S, Huang Y, Li YP, et al. RNA Helicase A Is an Important Host Factor Involved in Dengue Virus Replication. J Virol. 2019;93(4).

155. Matkovic R, Bernard E, Fontanel S, Eldin P, Chazal N, Hassan Hersi D, et al. The Host DHX9 DExH-Box Helicase Is Recruited to Chikungunya Virus Replication Complexes for Optimal Genomic RNA Translation. J Virol. 2019;93(4).

156. Kovalev N, Pogany J, Nagy PD. A Co-Opted DEAD-Box RNA helicase enhances tombusvirus plus-strand synthesis. PLoS Pathog. 2012;8(2):e1002537.

157. Wu CY, Nagy PD. Blocking tombusvirus replication through the antiviral functions of DDX17-like RH30 DEAD-box helicase. PLoS Pathog. 2019;15(5):e1007771.

158. Kato H, Takeuchi O, Sato S, Yoneyama M, Yamamoto M, Matsui K, et al. Differential roles of MDA5 and RIG-I helicases in the recognition of RNA viruses. Nature. 2006;441(7089):101-5.

159. Dalmay $T$, Horsefield R, Braunstein TH, Baulcombe DC. SDE3 encodes an RNA helicase required for posttranscriptional gene silencing in Arabidopsis. EMBO J. 2001;20(8):2069-78.

160. Carmell MA, Hannon GJ. RNase III enzymes and the 
initiation of gene silencing. Nat Struct Mol Biol. 2004;11(3):214-8

161. Seybert A, Posthuma CC, van Dinten LC, Snijder EJ, Gorbalenya AE, Ziebuhr J. A complex zinc finger controls the enzymatic activities of nidovirus helicases. J Virol. 2005;79(2):696-704.

162. Hao W, Wojdyla JA, Zhao R, Han R, Das R, Zlatev I, et al. Crystal structure of Middle East respiratory syndrome coronavirus helicase. PLoS Pathog. 2017;13(6):e1006474.

163. Seybert A, Hegyi A, Siddell SG, Ziebuhr J. The human coronavirus $229 \mathrm{E}$ superfamily 1 helicase has RNA and DNA duplex-unwinding activities with 5'-to-3' polarity. RNA. 2000;6(7):1056-68.

164. Ivanov KA, Ziebuhr J. Human coronavirus $229 \mathrm{E}$ nonstructural protein 13: characterization of duplexunwinding, nucleoside triphosphatase, and RNA 5'-triphosphatase activities. J Virol. 2004;78(14):7833-8.

165. Ivanov KA, Thiel V, Dobbe JC, van der Meer Y, Snijder EJ, Ziebuhr J. Multiple enzymatic activities associated with severe acute respiratory syndrome coronavirus helicase. J Virol. 2004;78(11):5619-32.

166. Tanner JA, Watt RM, Chai YB, Lu LY, Lin MC, Peiris JS, et al. The severe acute respiratory syndrome (SARS) coronavirus NTPase/helicase belongs to a distinct class of 5 to 3' viral helicases. J Biol Chem. 2003;278(41):39578-82.

167. Adedeji AO, Marchand B, Te Velthuis AJ, Snijder EJ, Weiss $\mathrm{S}$, Eoff RL, et al. Mechanism of nucleic acid unwinding by SARS-CoV helicase. PLoS One. 2012;7(5):e36521.

168. Lee NR, Kwon HM, Park K, Oh S, Jeong YJ, Kim DE. Cooperative translocation enhances the unwinding of duplex DNA by SARS coronavirus helicase nsP13. Nucleic Acids Res. 2010;38(21):7626-36

169. Seybert A, van Dinten LC, Snijder EJ, Ziebuhr J. Biochemical characterization of the equine arteritis virus helicase suggests a close functional relationship between arterivirus and coronavirus helicases. J Virol. 2000;74(20):9586-93.

170. Zhang R, Li Y, Cowley TJ, Steinbrenner AD, Phillips JM, Yount BL, et al. The nsp1, nsp13, and M proteins contribute to the hepatotropism of murine coronavirus JHM.WU. J Virol. 2015;89(7):3598-609.

171. Minskaia E, Hertzig T, Gorbalenya AE, Campanacci V, Cambillau C, Canard B, et al. Discovery of an RNA virus $3^{\prime}->5$ ' exoribonuclease that is critically involved in coronavirus RNA synthesis. Proc Natl Acad Sci U S A. 2006;103(13):5108-13.

172. Bouvet M, Imbert I, Subissi L, Gluais L, Canard B, Decroly E. RNA 3'-end mismatch excision by the severe acute respiratory syndrome coronavirus nonstructural protein nsp10/nsp14 exoribonuclease complex. Proc Natl Acad Sci U S A. 2012;109(24):9372-7.

173. Eckerle LD, Lu X, Sperry SM, Choi L, Denison MR. High fidelity of murine hepatitis virus replication is decreased in nsp14 exoribonuclease mutants. J Virol. 2007;81(22):12135-44.

174. Eckerle LD, Becker MM, Halpin RA, Li K, Venter E, Lu X, et al. Infidelity of SARS-CoV Nsp14-exonuclease mutant virus replication is revealed by complete genome sequencing. PLoS Pathog. 2010;6(5):e1000896.

175. Case JB, Li Y, Elliott R, Lu X, Graepel KW, Sexton NR, et al. Murine Hepatitis Virus nsp14 Exoribonuclease Activity Is Required for Resistance to Innate Immunity. J Virol. 2018;92(1).

176. Zhou Y, Wu W, Xie L, Wang D, Ke Q, Hou Z, et al. Cellular RNA helicase DDX1 is involved in transmissible gastroenteritis virus nsp14-induced interferon-beta production. Front Immunol. 2017;8:940.

177. Chen $\mathrm{Y}$, Cai H, Pan J, Xiang N, Tien P, Ahola T, et al. Functional screen reveals SARS coronavirus nonstructura protein nsp14 as a novel cap N7 methyltransferase. Proc Natl Acad Sci U S A. 2009;106(9):3484-9.

178. Jin $X$, Chen $Y$, Sun $Y$, Zeng C, Wang $Y$, Tao J, et al Characterization of the guanine-N7 methyltransferase activity of coronavirus nsp14 on nucleotide GTP. Virus Res. 2013;176(1-2):45-52.

179. Snijder EJ, Horzinek MC, Spaan WJ. The coronaviruslike superfamily. Adv Exp Med Biol. 1993;342:235-44.

180. Cavanagh D, Horzinek MC. Genus Torovirus assigned to the Coronaviridae. Arch Virol. 1993;128(3-4):395-6.

181. Zirkel F, Roth H, Kurth A, Drosten C, Ziebuhr J, Junglen S. Identification and characterization of genetically divergent members of the newly established family Mesoniviridae. J Virol. 2013;87(11):6346-58.

182. Nga PT, Parquet Mdel C, Lauber C, Parida M, Nabeshima T, $\mathrm{Yu} F$, et al. Discovery of the first insect nidovirus, a missing evolutionary link in the emergence of the largest RNA virus genomes. PLoS Pathog. 2011;7(9):e1002215.

183. Lauber C, Ziebuhr J, Junglen S, Drosten C, Zirkel F, Nga PT, et al. Mesoniviridae: a proposed new family in the order Nidovirales formed by a single species of mosquito-borne viruses. Arch Virol. 2012;157(8):1623-8.

184. Guarino LA, Bhardwaj K, Dong W, Sun J, Holzenburg A, Kao C. Mutational analysis of the SARS virus Nsp15 endoribonuclease: identification of residues affecting hexamer formation. J Mol Biol. 2005;353(5):1106-17.

185. Bhardwaj K, Guarino L, Kao CC. The severe acute respiratory syndrome coronavirus $\mathrm{Nsp} 15$ protein is an endoribonuclease that prefers manganese as a cofactor. $J$ Virol. 2004;78(22):12218-24.

186. Deng X, Baker SC. An "Old" protein with a new story: Coronavirus endoribonuclease is important for evading host antiviral defenses. Virology. 2018;517:157-63.

187. Zhang L, Li L, Yan L, Ming Z, Jia Z, Lou Z, et al. Structural and Biochemical Characterization of Endoribonuclease Nsp15 Encoded by Middle East Respiratory Syndrome Coronavirus. J Virol. 2018;92(22).

188. Bhardwaj K, Palaninathan S, Alcantara JM, Yi LL, Guarino L, Sacchettini JC, et al. Structural and functional analyses of the severe acute respiratory syndrome coronavirus endoribonuclease Nsp15. J Biol Chem. 2008;283(6):3655-64.

189. Bhardwaj K, Sun J, Holzenburg A, Guarino LA, Kao CC. RNA recognition and cleavage by the SARS coronavirus endoribonuclease. J Mol Biol. 2006;361(2):243-56.

190. Kang H, Bhardwaj K, Li Y, Palaninathan S, Sacchettini $\mathrm{J}$, Guarino L, et al. Biochemical and genetic analyses of murine hepatitis virus Nsp15 endoribonuclease. J Virol. 2007;81(24):13587-97.

191. Deng X, Hackbart M, Mettelman RC, O'Brien A, Mielech $A M, Y i G$, et al. Coronavirus nonstructural protein 15 mediates evasion of dsRNA sensors and limits apoptosis in macrophages. Proc Natl Acad Sci U S A. 2017;114(21):E4251-E60.

192. Decroly E, Ferron F, Lescar J, Canard B. Conventional and unconventional mechanisms for capping viral mRNA. Nat Rev Microbiol. 2011;10(1):51-65.

193. Decroly E, Imbert I, Coutard B, Bouvet M, Selisko B, Alvarez $\mathrm{K}$, et al. Coronavirus nonstructural protein 16 is a cap-0 binding enzyme possessing (nucleoside-2'O)methyltransferase activity. J Virol. 2008;82(16):8071-84.

194. Menachery VD, Yount BL, Jr., Josset L, Gralinski LE, Scobey $\mathrm{T}$, Agnihothram S, et al. Attenuation and restoration of severe acute respiratory syndrome coronavirus mutant lacking 2'-o-methyltransferase activity. J Virol. 2014;88(8):4251-64.

195. Zhang W, Zheng XS, Agwanda B, Ommeh S, Zhao K, Lichoti $\mathrm{J}$, et al. Serological evidence of MERS-CoV and HKU8related CoV co-infection in Kenyan camels. Emerg Microbes Infect. 2019;8(1):1528-34.

196. Reusken CB, Haagmans BL, Muller MA, Gutierrez C, Godeke GJ, Meyer B, et al. Middle East respiratory syndrome coronavirus neutralising serum antibodies in dromedary camels: a comparative serological study. Lancet Infect Dis. 2013;13(10):859-66.

197. Ge XY, Li JL, Yang XL, Chmura AA, Zhu G, Epstein JH, et al. Isolation and characterization of a bat SARS-like 
coronavirus that uses the ACE2 receptor. Nature. 2013;503(7477):535-8.

198. Li W, Shi Z, Yu M, Ren W, Smith C, Epstein JH, et al. Bats are natural reservoirs of SARS-like coronaviruses. Science. 2005;310(5748):676-9.

199. Hu B, Ge X, Wang LF, Shi Z. Bat origin of human coronaviruses. Virol J. 2015;12:221.

200. Banerjee A, Kulcsar K, Misra V, Frieman M, Mossman K. Bats and Coronaviruses. Viruses. 2019;11(1).

201. Brook CE, Boots M, Chandran K, Dobson AP, Drosten C Graham AL, et al. Accelerated viral dynamics in bat cell lines, with implications for zoonotic emergence. Elife. 2020;9.

202. Banerjee A, Baker ML, Kulcsar K, Misra V, Plowright R, Mossman K. Novel insights into immune systems of bats. Front Immunol. 2020;11:26.

203. Zumla A, Chan JF, Azhar EI, Hui DS, Yuen KY Coronaviruses - drug discovery and therapeutic options. Nat Rev Drug Discov. 2016;15(5):327-47.

204. Anand K, Ziebuhr J, Wadhwani P, Mesters JR, Hilgenfeld R. Coronavirus main proteinase (3CLpro) structure: basis for design of anti-SARS drugs. Science. 2003;300(5626):1763-7.

205. David A. Matthews, Amy K. Patick, Robert O. Baker, Mary A. Brothers, Peter S. Dragovich, Chris J. Hartmann, et al. In vitro antiviral activivty of human rhinovirus $3 \mathrm{C}$ protease inhibitors against the SARS coronavirus. In: Knobler S, Mahmoud A, Lemon S, Mack A, Sivitz L, Oberholtzer K, editors. Learning from SARS: Preparing for the Next Disease Outbreak: Workshop Summary. The National Academies Collection: Reports funded by National Institutes of Health. Washington (DC): National Academies Press (US); 2004.

206. Yang H, Xie W, Xue X, Yang K, Ma J, Liang W, et al. Design of wide-spectrum inhibitors targeting coronavirus main proteases. PLoS Biol. 2005;3(10):e324.

207. Ren Z, Yan L, Zhang N, Guo Y, Yang C, Lou Z, et al. The newly emerged SARS-like coronavirus HCoV-EMC also has an "Achilles' heel": current effective inhibitor targeting a 3C-like protease. Protein Cell. 2013;4(4):248-50.

208. de Wilde AH, Jochmans D, Posthuma CC, ZevenhovenDobbe JC, van Nieuwkoop S, Bestebroer TM, et al. Screening of an FDA-approved compound library identifies four small-molecule inhibitors of Middle East respiratory syndrome coronavirus replication in cell culture. Antimicrob Agents Chemother. 2014;58(8):4875-84.

209. Chu CM, Cheng VC, Hung IF, Wong MM, Chan KH, Chan KS, et al. Role of lopinavir/ritonavir in the treatment of SARS: initial virological and clinical findings. Thorax. 2004;59(3):252-6.

210. Chan KS, Lai ST, Chu CM, Tsui E, Tam CY, Wong MM, et al. Treatment of severe acute respiratory syndrome with lopinavir/ritonavir: a multicentre retrospective matched cohort study. Hong Kong Med J. 2003;9(6):399-406.

211. Chan JF, Yao Y, Yeung ML, Deng W, Bao L, Jia L, et al. Treatment With Lopinavir/Ritonavir or Interferon-beta1b Improves Outcome of MERS-CoV Infection in a Nonhuman Primate Model of Common Marmoset. J Infect Dis. 2015;212(12):1904-13.

212. Agnihothram S, Yount BL, Jr., Donaldson EF, Huynh J,
Menachery VD, Gralinski LE, et al. A mouse model for Betacoronavirus subgroup $2 \mathrm{c}$ using a bat coronavirus strain HKU5 variant. mBio. 2014;5(2):e00047-14.

213. Zhang Q, Wang Y, Qi C, Shen L, Li J. Clinical trial analysis of 2019-nCoV therapy registered in China. J Med Virol. 2020 Feb 28. [Epub ahead of print]

214. Li G, De Clercq E. Therapeutic options for the 2019 novel coronavirus (2019-nCoV). Nat Rev Drug Discov. 2020;19(3):149-50.

215. Cao B, Wang Y, Wen D, Liu W, Wang J, Fan G, et al. A trial of lopinavir-ritonavir in adults hospitalized with severe Covid-19. N Engl J Med. 2020 Mar 18. [Epub ahead of print]

216. Lin $\mathrm{MH}$, Moses DC, Hsieh $\mathrm{CH}$, Cheng SC, Chen $\mathrm{YH}$, Sun $C Y$, et al. Disulfiram can inhibit MERS and SARS coronavirus papain-like proteases via different modes. Antiviral Res. 2018;150:155-63.

217. Lee H, Ren J, Pesavento RP, Ojeda I, Rice AJ, Lv H, et al. Identification and design of novel small molecule inhibitors against MERS-CoV papain-like protease via high-throughput screening and molecular modeling. Bioorg Med Chem. 2019;27(10):1981-9.

218. Cheng KW, Cheng SC, Chen WY, Lin MH, Chuang SJ, Cheng $\mathrm{IH}$, et al. Thiopurine analogs and mycophenolic acid synergistically inhibit the papain-like protease of Middle East respiratory syndrome coronavirus. Antiviral Res. 2015;115:9-16.

219. Wang $M$, Cao R, Zhang L, Yang X, Liu J, Xu M, et al. Remdesivir and chloroquine effectively inhibit the recently emerged novel coronavirus (2019-nCoV) in vitro. Cell Res. 2020;30(3):269-71.

220. Adedeji AO, Singh K, Calcaterra NE, DeDiego ML, Enjuanes $\mathrm{L}$, Weiss $\mathrm{S}$, et al. Severe acute respiratory syndrome coronavirus replication inhibitor that interferes with the nucleic acid unwinding of the viral helicase. Antimicrob Agents Chemother. 2012;56(9):4718-28.

221. Yu MS, Lee J, Lee JM, Kim Y, Chin YW, Jee JG, et al. Identification of myricetin and scutellarein as novel chemical inhibitors of the SARS coronavirus helicase, nsP13. Bioorg Med Chem Lett. 2012;22(12):4049-54.

222. Tanner JA, Zheng BJ, Zhou J, Watt RM, Jiang JQ, Wong $\mathrm{KL}$, et al. The adamantane-derived bananins are potent inhibitors of the helicase activities and replication of SARS coronavirus. Chem Biol. 2005;12(3):303-11.

223. Yang XH, Deng W, Tong Z, Liu YX, Zhang LF, Zhu H, et al. Mice transgenic for human angiotensin-converting enzyme 2 provide a model for SARS coronavirus infection. Comp Med. 2007;57(5):450-9.

224. Li K, Wohlford-Lenane CL, Channappanavar R, Park JE, Earnest JT, Bair TB, et al. Mouse-adapted MERS coronavirus causes lethal lung disease in human DPP4 knockin mice. Proc Natl Acad Sci U S A. 2017;114(15):E3119-E28.

225. Baric RS, Sims AC. Humanized mice develop coronavirus respiratory disease. Proc Natl Acad Sci U S A. 2005;102(23):8073-4.

226. Meszaros B, Erdos G, Dosztanyi Z. IUPred2A: contextdependent prediction of protein disorder as a function of redox state and protein binding. Nucleic Acids Res. 2018;46(W1):W329-W37. 